\title{
Three-dimensional Solution Structure and Backbone Dynamics of a Variant of Human Interleukin-3
}

\author{
Yiqing Feng*, Barbara K. Klein and Charles A. McWherter*
}

\author{
G.D. Searle and Company \\ 700 Chesterfield \\ Parkway North, St. Louis \\ MO 63198, USA
}

The three-dimensional structure and backbone dynamics of a truncated
and multiply substituted recombinant human interleukin-3 (IL-3) variant
(SC-65369) have been determined from multidimensional heteronuclear
nuclear magnetic resonance spectroscopic data. Sequential application of
distance geometry and restrained molecular dynamics calculations
produced a family of 25 convergent structures which satisfy a total of 1812
experimental constraints (1659 proton-proton NOEs, 75 backbone dihedral angle constraints, and 39 pairs of hydrogen bond constraints) with an average root-mean-square deviation from the mean coordinate positions of $0.88( \pm 0.15) \AA$ and $1.37( \pm 0.13) \AA$ for the backbone and all heavy atoms, respectively, of all residues except 28 to 39 . The structure is a left-handed four-helix bundle (comprised of helices A through D) with two long overhand loops (designated as loops $\mathrm{AB}$ and $\mathrm{CD}$ ). Loop $\mathrm{AB}$ contains a short fifth helix (helix $A^{\prime}$ ) which is closely packed against helix $D$ in an approximately parallel fashion and which has multiple contacts with loop CD. The overall molecular tumbling time $(6.5 \mathrm{~ns})$ determined from the ${ }^{15} \mathrm{~N}$ relaxation data was consistent with a monomeric protein under the conditions of the experiment $\left(1 \mathrm{mM}\right.$ protein, $\left.\mathrm{pH} 4.6,30^{\circ} \mathrm{C}\right)$. The ${ }^{15} \mathrm{~N}$ relaxation data indicate that the helical regions of SC-65369 are quite rigid, while portions of loop $\mathrm{AB}$, loop $\mathrm{CD}$, and the $\mathrm{C}$ terminus undergo significant internal motions. Among the structurally related four-helical bundle cytokines, the structure of SC-65369 is most similar to those of granulocyte-macrophage colony stimulating factor (GM-CSF) and the single structural domain of interleukin-5 (IL-5), all of which share a common receptor subunit required for signal transduction and activation of their hematopoietic target cells. Indeed, the $\mathrm{C}^{\alpha}$ atoms in the four-helix core of these three proteins can be superimposed to $1.71 \AA$ (SC-65369 and GM-CSF, $62 \mathrm{C}^{\alpha}$ atoms) and $1.96 \AA$ (SC-65369 and IL-5 single structural domain, $58 \mathrm{C}^{\alpha}$ atoms), respectively. When the structures of the IL-3 variant, GM-CSF, and IL-5 were aligned, the conserved and conservatively substituted residues were found to be hydrophobic and buried, with the single exception of Glu-22 (IL-3 numbering), which is strictly conserved but nonetheless fully exposed to solvent. The most remarkable differences between the SC-65369 structure and that of GM-CSF occur in loop AB. This loop in GM-CSF crosses over the top of helix D and passes underneath loop CD on its way to helix B. In contrast, loop AB of SC-65369 passes in front of helix D, similar to the first crossover loop in human growth hormone and granulocyte colony-stimulating factor. In addition, helix $\mathrm{A}^{\prime}$, which is interdigitated into the helical bundle in a manner similar to the helices in the CD loop of interferon- $\beta$ and interferon- $\gamma$, exists in a region where short stretches of $\beta$-structure are found at analogous positions in GM-CSF and

${ }^{*}$ Corresponding authors

\begin{abstract}
stretch of $\beta$-structure are found at analogous positions in GM-CSF and
\end{abstract}
Abbreviations used: IL-3, interleukin-3; hIL-3, human IL-3; SC-65369, a truncated variant of hIL-3 mutated in 14 of 112 positions; GM-CSF, granulocyte-macrophage colony stimulating factor; IL-5, interleukin-5; IFN- $\beta$, interferon- $\beta$; IFN- $\gamma$, interferon- $\gamma$; IL-2, interleukin-2; IL-4, interleukin-4; G-CSF, granulocyte colony stimulating factor; M-CSF, macrophage colony stimulating factor; GH, growth hormone; GHR, growth hormone receptor; PRLR, prolactin receptor; LIF, Leukemia Inhibitory Factor; NOE, nuclear Overhauser effect; r.m.s.d., root-mean-square deviation; NOESY, nuclear Overhauser effect spectroscopy; ROESY, rotating-frame NOESY; HMQC, heteronuclear multiple-quantum coherence; HSQC, heteronuclear single-quantum coherence; 3D, three-dimensional; PDB, Protein Data Bank. 
IL-5. These differences suggest that the structural elements within this region may be important for recognition by their cognate receptors.

(C) 1996 Academic Press Limited

Keywords: cytokine structure; four-helical bundle; growth factor; ${ }^{15} \mathrm{~N}$ NMR relaxation; dynamics

\section{Introduction}

Human interleukin-3 (IL-3) is a 133-residue glycoprotein (Yang et al., 1986) produced by activated T-lymphocytes (Schrader \& Clark-Lewis, 1982; Gough \& Kelso, 1989; Nishida et al., 1991), which is important for the growth and differentiation of primitive hematopoietic cells (reviewed by Metcalf \& Nicola, 1995). Secondary structural predictions (Parry et al., 1988, 1991) led to its classification as a helical cytokine (Bazan, 1990; Rozwarski et al., 1994), a family of proteins with a characteristic up-up-down-down four- $\alpha$-helical topology that serve as important regulators of hematopoiesis, as well as mediating immune and inflammatory responses. The initial biophysical characterization of recombinant IL-3 and IL-3 variants by CD (Freeman et al., 1991; R. Schilling \& R. McKinnie, unpublished results) and NMR spectroscopy (Feng et al., 1995) have served to confirm this designation. Stimulation of the IL-3 receptor on immature multipotential and lineage-restricted hematopoietic progenitors, either alone or in the presence of other cytokines, leads to their proliferation and thereby enhances the development of erythrocytes, platelets, macrophages, neutrophils, basophils, and eosinophils (Metcalf \& Nicola, 1995). These properties make IL-3 a promising therapeutic candidate for the treatment of chemotherapy-induced neutropenia and thrombocytopenia (Ganser et al., 1990; Herrmann et al., 1992; Ganser, 1993). However, pro-inflammatory effects, such as the stimulation of histamine release by basophils (Haak-Frendscho et al., 1988), degranulation of eosinophils (Lopez et al., 1989), and the priming of peripheral blood leukocytes for the release of sulfidoleukotrienes, may limit its clinical utility (Biesma et al., 1992; Denzlinger et al., 1993). In an effort to overcome these limitations, extensive mutagenesis of truncated hIL-3 led to the identification of molecules with 10 to 20 -fold greater proliferative and colony forming activity relative to hIL-3, but with only a twofold increase in potentiation of histamine and sulfidoleukotriene release (Thomas et al., 1995).

IL-3 is related to GM-CSF and IL-5, two short-chain cytokines (Rozwarski et al., 1994) with which it shares a post-receptor signaling pathway (reviewed by Mui et al., 1994) that entails protein tyrosine phosphorylation of the receptor in the membrane proximal cytoplasmic domain by JAK2 kinase (Quelle et al., 1994) and induction of isoforms of the cytoplasmic transcriptional activator STAT5 (Azam et al., 1995). The receptors for each of these cytokines are heterodimeric transmembrane pro- teins consisting of a specific low affinity alpha subunit (IL-3R $\alpha$, Kitamura et al., 1991; GMR $\alpha$, Gearing et al., 1989; IL-5R $\alpha$, Tavernier et al., 1991) and a common signal-transducing beta subunit $\left(\beta_{C}\right.$; Hayashida et al., 1990; Kitamura et al., 1991; Tavernier et al., 1991). Although the alpha subunits are able to bind to their cognate cytokines $\left(K_{\mathrm{d}} \sim 1 \times 10^{-7}\right.$ to $\left.1 \times 10^{-9} \mathrm{M}\right)$, this is not usually sufficient to signal (for an exception, see Ding et al., 1994). Conversely, in the absence of the low affinity subunits, there is no detectable binding of any of the cytokines by $\beta_{C}$; signal transduction relies on formation of a high affinity ternary complex between cytokine and its heterodimeric receptor $\left(K_{\mathrm{d}} \sim 1 \times 10^{-10} \mathrm{M}\right.$; Kitamura et al., 1991; Kitamura \& Miyajima, 1992; Takaki et al., 1993). The three-dimensional structures of GM-CSF (Diederichs et al., 1991; Walter et al., 1992) and IL-5 (Milburn et al., 1993) have been determined by X-ray crystallography and have been found to have a four- $\alpha$-helical bundle motif that is common among the cytokines such as IFN- $\gamma$ (Ealick et al., 1991), IL-2 (Bazan, 1992; McKay, 1992; Mott et al., 1992), IFN- $\beta$ (Senda et al., 1992), IL-4 (Smith et al., 1992; Powers et al., 1992; Wlodawer et al., 1992), M-CSF (Pandit et al., 1992), G-CSF (Hill et al., 1993; Lovejoy et al., 1993; Zink et al., 1992, 1994; Werner et al., 1994), GH (Abdel-Meguid et al., 1987; de Vos et al., 1992; Somers et al., 1994), LIF (Robinson et al., 1994), and IL-10 (Walter \& Nagabhushan, 1995).

Numerous mutagenesis and epitope mapping studies of IL-3 (Olins et al., 1995; Lopez et al., 1992a; Kaushansky et al., 1992; Dorssers et al., 1991; Lokker et al., 1991a,b), GM-CSF (Brown et al., 1994; Shanafelt et al., 1991a,b; Lopez et al., 1992b; and others reviewed in Metcalf \& Nicola, 1995) and IL-5 (Tavernier et al., 1994; Banks et al., 1995; Graber et al., 1995), as well as mutagenesis of $\beta_{\mathrm{C}}$ (Woodcock et al., 1994; Bagley et al., 1995), have begun to define the interactions involved in receptor affinity and selectivity. In order to provide a more complete basis for interpreting these studies, we initiated a project to determine the three-dimensional structure of a soluble variant of hIL-3 (SC-65369) using multi-dimensional heteronuclear NMR techniques. In a previous paper, we reported the ${ }^{1} \mathrm{H},{ }^{15} \mathrm{~N}$, and ${ }^{13} \mathrm{C}$ NMR resonance assignments, the secondary structure, and the chain-folding topology of SC-65369 (Feng et al., 1995). In this paper, we report the three-dimensional structure and backbone ${ }^{15} \mathrm{~N}$ dynamics of SC-65369. The overall fold of the hIL-3 variant has a mixture of short-chain, long-chain, and interferon-like helical cytokine features (Rozwarski et al., 1994). The small helix in the first overhand loop was found to be an integral part of 
the structure with an average atomic r.m.s.d. and rigid-body tumbling motion similar to that of the four-helical core. In contrast, the loops undergo significant internal motions in addition to the overall tumbling. A comparison of the structures of the IL-3 variant, GM-CSF, and IL-5 suggests that the $\mathrm{AB}$ loop region could be important for receptor recognition, a hypothesis that is supported by results to be reported elsewhere (B. K. Klein, unpublished results).

\section{Results}

SC-65369 is a truncated and multiply substituted variant of hIL-3 (P. Olins \& C. Bauer, unpublished results). It was chosen for study because (1) it is sufficiently soluble and stable for NMR studies, whereas wild-type IL-3 is not, (2) it is fully active in cell proliferation and receptor binding assays (P. Olins, C. Bauer, J. Thomas, W. Hood, unpublished results), and (3) it is closely related to SC-55494 (Thomas et al., 1995), a similarly truncated and multiply substituted hIL-3 variant which has a 10 to 20-fold increase in its growth promoting activity and which is undergoing clinical evaluation for reducing the degree and duration of chemotherapy-induced cytopenias. Previously, the ${ }^{1} \mathrm{H},{ }^{13} \mathrm{C}$ and ${ }^{15} \mathrm{~N}$ resonance assignments, secondary structure and chain folding topology of SC-65369 have been determined using ${ }^{13} \mathrm{C} /{ }^{15} \mathrm{~N}$-enriched samples of SC-65369 (Feng et al., 1995). In addition to the expected four-helical bundle, an unexpected observation was the small helix designated as helix $\mathrm{A}^{\prime}$ in the loop connecting the first two helices (helices A and B). A complicating feature of the analysis was the doubling of a subset of resonances, which could be localized to regions that are close in sequence or space to a proline-rich segment of the first overhand loop. After eliminating the possibility of chemical heterogeneity, these results suggested that SC-65369 exists in two or more conformational forms whose origins are highly localized and that may arise from slow cis-trans isomerization of proline peptide bonds.

\section{Structure calculations}

SC-65369 contains 112 amino acid residues and one intramolecular disulfide bond between Cys16 and Cys84. As reported by Feng et al. (1995), chemical shift heterogeneity was observed for a number of residues with a ratio of intensities of approximately $1: 1$, and the impact of such heterogeneity on the structure was determined to be rather local because the pattern of resolved short, medium and long-range nuclear Overhauser effects (NOEs) was nearly identical for both sets of

+ On the basis of the work of Liepinsh et al. (1992), the potential for an NOE from a protonated side-chain carboxyl group can be ruled out. signals. Because there is no reliable way to distinguish signals arising from each of the two conformers, a simple averaging method was employed to determine NOE intensities. Whenever heterogeneous chemical shifts were encountered and both resonances exhibited an unambiguous NOE to a third proton, the two NOE intensities were summed and the total intensity was used in the distance classification. When one of the two NOEs was not sufficiently resolved, the intensity of the other, resolved NOE was doubled prior to being classified. Nearly all the measurable heterogeneous sites had virtually identical ${ }^{3} \mathrm{~N}_{\mathrm{NH} \alpha}$, and so no such averaging of coupling constants was necessary. Following this approach, a total of 1812 experimental constraints were used to determine the structure of SC-65369. These are comprised of 1659 interproton distance constraints (14.8 per residue), 75 backbone dihedral angle constraints, and 39 pairs of hydrogen bond constraints. A further breakdown of these NOEs is provided in Table 1, and their distribution along the sequence is illustrated in Figure 1(a).

At an intermediate stage of the structure calculations, the position of the segment spanning from residues 28 to 39 was poorly defined due to the lack of long-range NOEs. A pair of ambiguous NOEs were identified that could be used to help locate this segment as follows. The amide protons of Gly102 and Asp103 both displayed cross-peaks with proton partners that resonate at $4.70 \mathrm{ppm}$. Examination of the preliminary structures identified the $\mathrm{C}^{\alpha} \mathrm{H}$ of Asn38 and Asn39, both of which resonate at $4.70 \mathrm{ppm}$, as likely candidate NOE partners. However, because residual solvent resonates at an identical position, it was necessary to use three-dimensional (3D) ROESY-HSQC data to show that these cross-peaks were due to cross-relaxation (NOE) rather than to an exchange process (results not shown)t. The alternative assignments were investigated by calculating a family of 23 convergent structures with these two NOEs included as ambiguous restraints (Nilges, 1995). The resulting convergent structures could be divided into two families. In family A (15 structures), both the distance between $\mathrm{NH}$ of Gly102 and $\mathrm{C}^{\alpha} \mathrm{H}$ of Asn38 and that between $\mathrm{NH}$ of Asp103 and the $\mathrm{C}^{\alpha} \mathrm{H}$ of Asn 38 were ca. $5.0 \AA$, while the distance between $\mathrm{NH}$ of Gly102 and $\mathrm{C}^{\alpha} \mathrm{H}$ of Asn39 and that between $\mathrm{NH}$ of Asp103 and the $\mathrm{C}^{\alpha} \mathrm{H}$ of Asn-39 were larger than $7.0 \mathrm{~A}$. The reverse was true for family $\mathrm{B}$ (eight structures), where the distances from the $\mathrm{NH}$ groups of Gly102 and Asp103 to Asn39 were ca. $5.0 \AA$ and the distances to Asn 38 were greater than $7.0 \AA$ for all structures except one $(6.6 \AA)$. The results indicated that the structures were slightly in favor of both NOEs assigned solely to Asn38. Therefore a family of 25 convergent structures was calculated with both NOEs assigned to Asn38. The use of ambiguous NOEs to locate this segment, while not unequivocal, is nonetheless based on alternative interpretations of experimental data, and none of the conclusions of this study is 
Table 1. Structural statistics of 25 convergent structures of SC-65369

\begin{tabular}{|c|c|c|}
\hline A. Structural statistics & $\langle\mathrm{SA}\rangle$ & $\langle\overline{\mathrm{SA}}\rangle_{\mathrm{r}}$ \\
\hline $\begin{array}{l}\text { r.m.s.d. (A) from exptl distance restraints } \\
\text { All (1737) }\end{array}$ & & \\
\hline All (1737) & $0.045( \pm 0.002)$ & 0.043 \\
\hline Intraresidue (799) & $0.032( \pm 0.002)$ & 0.032 \\
\hline Sequential (342) & $0.049( \pm 0.003)$ & 0.047 \\
\hline Interresidue short $(1<|i-j| \leqslant 5)(236)$ & $0.055( \pm 0.005)$ & 0.05 \\
\hline Interresidue long $(|i-j|>5)(282)$ & $0.059( \pm 0.006)$ & 0.056 \\
\hline Hydrogen bond (78) & $0.048( \pm 0.006)$ & 0.046 \\
\hline r.m.s.d. (deg.) from exptl dihedral restraints (75) & $0.74( \pm 0.10)$ & 0.78 \\
\hline \multicolumn{3}{|l|}{ r.m.s.d. from idealized geometry } \\
\hline $\begin{array}{l}\text { Bonds ( } \AA \text { ) } \\
\text { Angles (deg.) }\end{array}$ & $\begin{array}{r}0.005( \pm 0.000) \\
0.90(+0.01)\end{array}$ & $\begin{array}{l}0.005 \\
0.87\end{array}$ \\
\hline $\begin{array}{l}\text { Angles (deg.) } \\
\text { Impropers (deg.) }\end{array}$ & $0.57( \pm 0.02)$ & 0.55 \\
\hline $\begin{array}{l}\text { B. Atomic r.m.s.d. }(\AA) \\
\langle\mathrm{SA}\rangle \text { versus }\langle\overline{\mathrm{SA}}\rangle\end{array}$ & Backbone & All non-H \\
\hline All residues & $1.38( \pm 0.35)$ & $1.89( \pm 0.31)$ \\
\hline All residues except $28-39$ & $0.88( \pm 0.15)$ & $1.37( \pm 0.13)$ \\
\hline $\begin{array}{l}\text { Helices A to D \& A' (residues } 16-26 \text {, } \\
54-67,72-84,104-122,42-49 \text { ) }\end{array}$ & $0.41( \pm 0.06)$ & $0.90( \pm 0.06)$ \\
\hline C. Violations of exptl restraints & $\langle\mathrm{SA}\rangle$ & $\langle\overline{\mathrm{SA}}\rangle_{\mathrm{r}}$ \\
\hline \multicolumn{3}{|l|}{ Distance restraints } \\
\hline No. $>0.3 \AA$ & $11.1( \pm 1.8)$ & 9 \\
\hline No. $>0.1 \AA$ & $66.3( \pm 6.1)$ & 57 \\
\hline \multicolumn{3}{|l|}{ Dihedral restraints } \\
\hline No. $>3$ deg. & $1.0( \pm 0.7)$ & 0 \\
\hline No. $>1$ deg. & $8.3( \pm 1.8)$ & 8 \\
\hline
\end{tabular}

substantively altered by assigning these NOEs to Asn38.

The 25 simulated annealing (SA) structures satisfy the input experimental constraints with no distance violations greater than $0.5 \AA$ or torsion angle violations greater than $5^{\circ}$, and they exhibit only small deviations from idealized covalent geometry and maintain good non-bonded contacts. A summary of statistics comparing these structures to one another and their average, and the violations of experimental restraints, is given in Table 1. Plots of the average atomic coordinate r.m.s.d. values, the backbone dihedral angles, and the solvent-accessible area for individual residues are shown in Figure 1(b) through (d), respectively. In the energyminimized average structure, the backbone conformations of all except Asn38, Asn70, and Gln124 of the non-glycine residues fall within the energetically favored regions of the Ramachandran plot (Figure 2); the positive $\phi$ angle of Asn70 is expected for the $i+3$ residue of a type II turn, and Asn 38 and Gln124 are in poorly defined regions with few NOE constraints. The superposition of backbone $\mathrm{N}, \mathrm{C}^{\alpha}, \mathrm{C}^{\prime}$ of the 25 structures is shown in Figure 3. The structures are well-defined except for the C terminus and the overhand loop between the first and second helices. The average r.m.s.d. between backbone $\mathrm{N}, \mathrm{C}^{\alpha}, \mathrm{C}^{\prime}$ and heavy atoms excluding the poorly defined long segment (i.e. residues 28 to 39) are 0.88 and $1.37 \AA$, respectively; when all residues are included, the backbone and heavy atom average r.m.s.d values increase to 1.38 and $1.89 \AA$, respectively. It can be seen that the helical segments comprising the four-helix bundle and the additional helix (see below) have relatively low average r.m.s.d. values. Indeed, when the average r.m.s.d. is calculated by restricting it to the helical regions, it is reduced to 0.41 and $0.90 \AA$ for backbone and heavy atoms, respectively.

\section{The structure of SC-65369}

A ribbon diagram of the minimized average structure $\left(\langle\overline{\mathrm{SA}}\rangle_{\mathrm{r}}\right)$ is shown in Figure 4 . The overall dimensions are approximately $45 \AA \times 37 \AA \times 30 \AA$. As suggested in the preliminary NMR analysis (Feng et al., 1995), SC-65369 is a compact molecule that displays the familiar up-up-down-down fourhelix bundle topology. The core of the structure contains four amphipathic helices, which are designated as helices A, B, C, and D according to the order of their occurrence in the sequence. The first long overhand loop is referred to as loop $A B$, which can be further subdivided into three portions consisting of a long loop (loop AA'), followed by a smaller helix termed helix $\mathrm{A}^{\prime}$, and finishing with a type I turn that connects helix $\mathrm{A}^{\prime}$ to helix B (turn $\left.A^{\prime} B\right)$. A type II turn is found at the C-terminal end of helix B, which results in a chain reversal just before the initiation of helix $\mathrm{C}$. A long segment that lacks regular secondary structure connects helix $\mathrm{C}$ to helix $\mathrm{D}$ and thereby forms the second and last long overhand loop (loop CD) in the SC-65369 structure.

Analysis of the minimized average structure with the program DSSP (Kabsch \& Sander, 1983) defines 

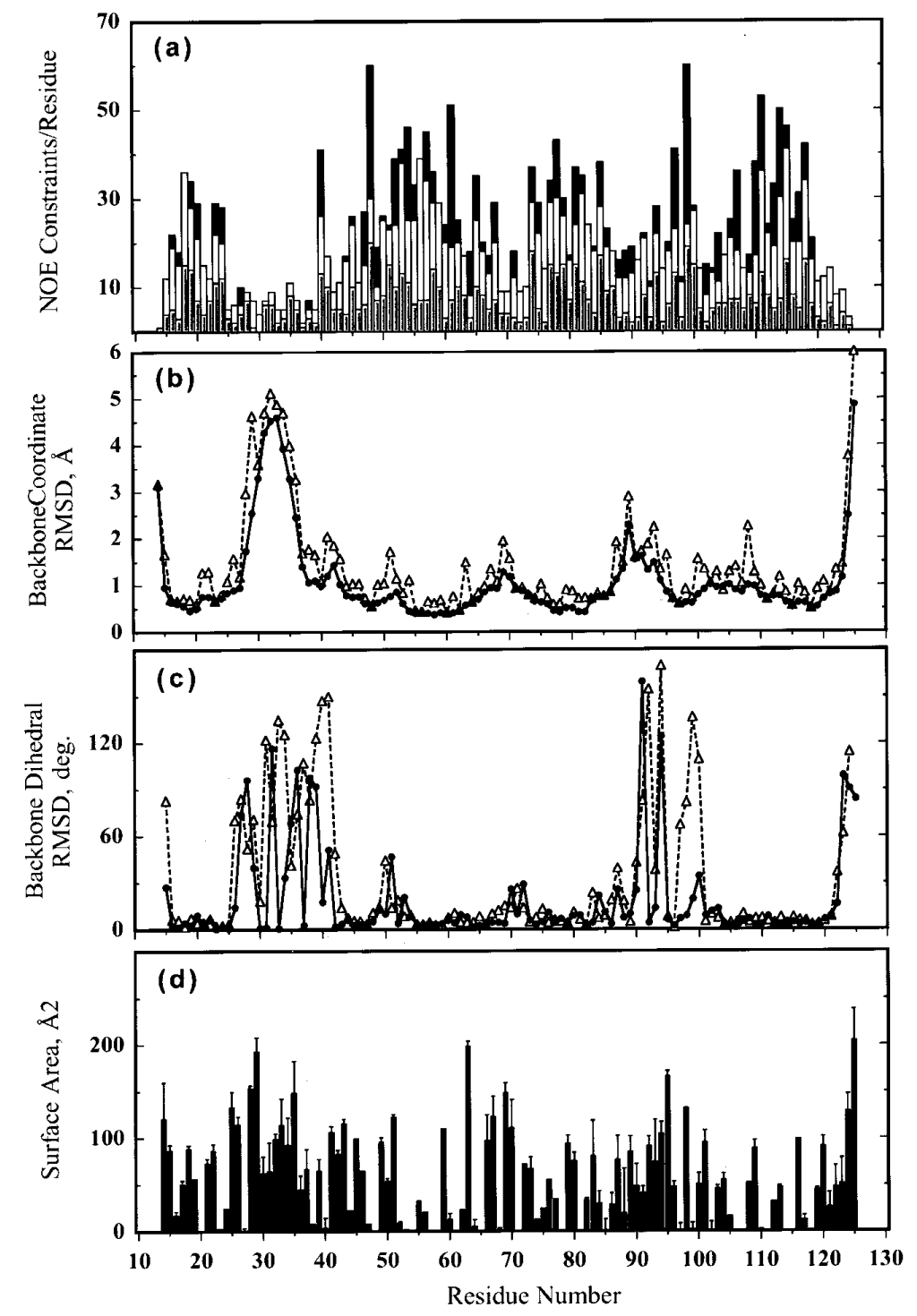

Figure 1. (a) Bar diagram illustrating the number of NOE constraints per residue. Gray-filled bars indicate intraresidue constraints, open bars indicate sequential and medium range $(|i-j| \leqslant 5)$ constraints, and filled bars indicate long range $(|i-j|>5)$ constraints. (b) Average atomic r.m.s.d. per residue: $\mathbf{0}$, backbone r.m.s.d.; $\triangle$, heavy atoms r.m.s.d. (c) r.m.s.d. of backbone dihedral angles. Torsion angles $\phi$ and $\psi$ are indicated with $\triangle$ and $\triangle$, respectively. (d) Solvent-accessible surface area of the minimized average structure of SC-65369 calculated with a probe size $1.4 \AA$. The error bars represent the r.m.s.d surface area calculated from the 25 convergent structures. five helical regionst: residues 16 to 26 (helix A), residues 42 to 49 (helix A'), residues 54 to 67 (helix B), residues 72 to 84 (helix C) with residues 82 to 84 identified as having a $3_{10}$ helical conformation, and residues 104 to 122 (helix D). Helix A (11 residues) and helix D (19 residues) form one layer of approximately antiparallel helices, while helix B (14 residues) and helix $C$ (13 residues) form another layer of antiparallel helices. Helix $A^{\prime}$ (eight residues), which occurs at the end of loop $A B$, is nearly parallel to helix D. A substantial loss of surface area (ca $25 \%$ of each of the four helices) occurs upon formation of the core four-helix

+ Note that the ${ }^{3} J_{\mathrm{NH} \alpha}$ coupling constants of His67 $(9.9 \mathrm{~Hz}), \mathrm{Cys} 84(8.2 \mathrm{~Hz})$, and $\mathrm{Gln} 122(6.9 \mathrm{~Hz})$ are inconsistent with their assignment to a helical conformation as made by the program DSSP. The $\phi$ angles for His67, Cys84, and Gln122 are $-89.2^{\circ},-89.6^{\circ}$, and $-75.7^{\circ}$ in the minimized average structure, respectively, while those of His67 and Cys84 are restrained to be between $-150^{\circ}$ and $-90^{\circ}$. bundle, thus indicating that the helices interact extensively. On the basis of visual inspection, as well as the calculated solvent-accessible surface areas, a hydrophobic core can be identified which consists of Ile20, Ile23, Leu27, Leu58, Phe61, Va165, Leu68, Ala71, Ile74, Leu78, Leu81, Leu85, Ile97, Phe107, Leu111, Tyr114, Leu115 and Leu118; most of these residues are in the four helices and are likely to have a significant role in maintaining the global fold of hIL3. The low r.m.s.d. for helix A' in the family of converged structures, the burial of $53 \%$ of its surface area, as well as the backbone dynamics data for this region as discussed below, indicate that helix $\mathrm{A}^{\prime}$ is packed tightly to helix $\mathrm{D}$ and loop $\mathrm{CD}$, and that it is an integral part of the bundle.

As mentioned previously, loop $\mathrm{AB}$ is the crossover loop which serves to connect helices $\mathrm{A}$ and $\mathrm{B}$, which are diagonally opposed to one another in the bundle. Thus, loop AB traverses not only the length of the bundle, but also its width. Loop AA', which constitutes the first part of loop $A B$, is less well 


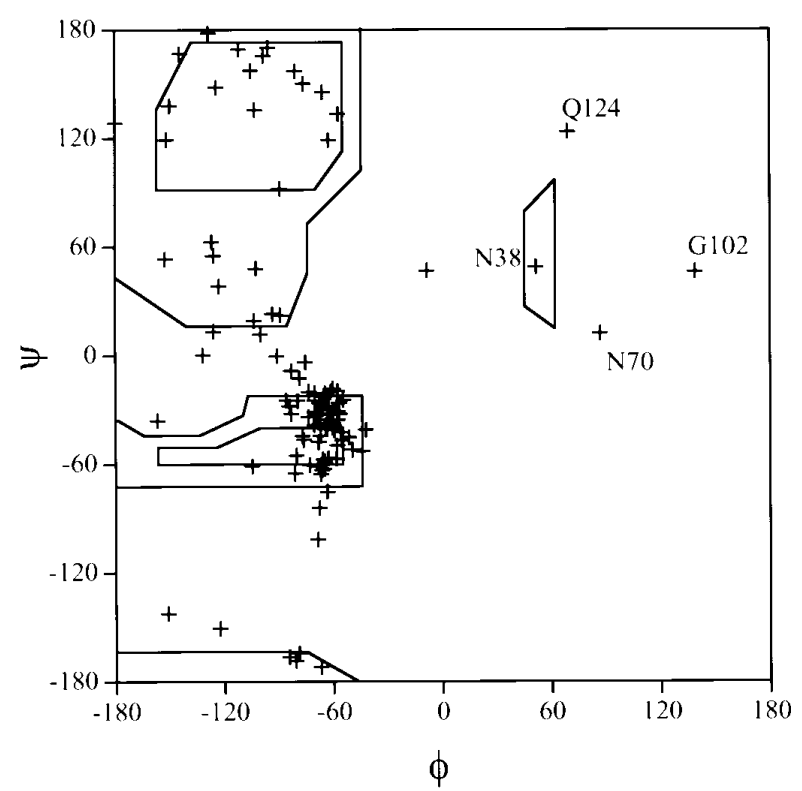

Figure 2. Ramachandran plot of the energy-minimized average structure of SC-65369. Gly102 and the three non-glycine residues with positive $\phi$ angles are labelled.

defined due to the paucity of long-range NOEs in this region. Nonetheless, it is tethered by helix A and helix $\mathrm{A}^{\prime}$ and is placed in front of the N-terminal end of helix $\mathrm{D}$. The backbone ${ }^{15} \mathrm{~N}$ dynamics data described below suggest that this segment is relatively flexible (see Figure 5), correlating with the high average r.m.s.d. in this region (Figure 1(b)). In contrast, residues in loop $\mathrm{CD}$ exhibit numerous long-range NOEs to helix A', helix B, and helix D, and as a result loop $C D$ is intimately wrapped around helix A' and helix $\mathrm{D}$, as it too traverses both the length and the breadth of the helical core. No NOE evidence was found for loop $\mathrm{AA}^{\prime}$ to pass

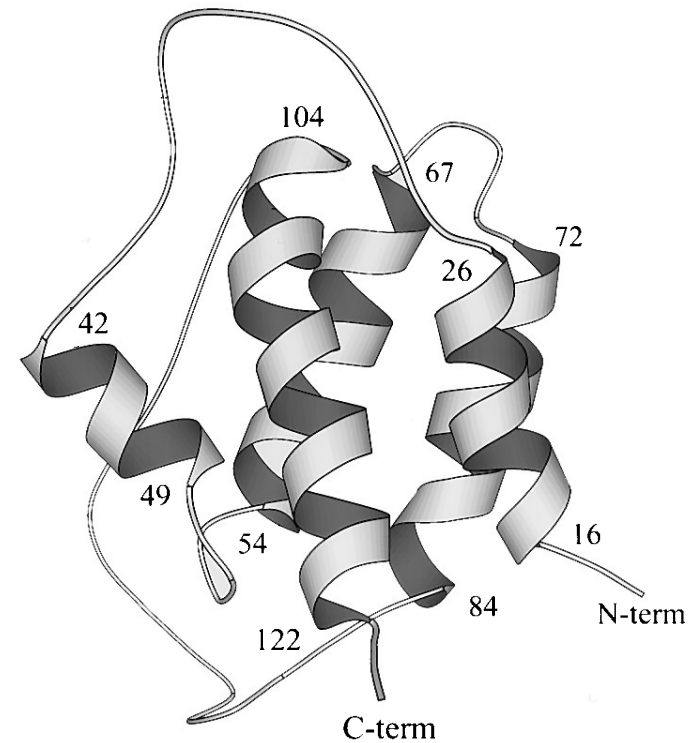

Figure 4. Ribbon diagram of the minimized average structure of SC-65369 illustrated using MOLSCRIPT (Kraulis, 1991). The residue numbers indicated designate the beginning and end of each helix as defined by the program DSSP (Kabsch \& Sander, 1983).

underneath loop $\mathrm{CD}$, as the analogous sequences do in GM-CSF or IL-4. To be certain that the topology of loop AA' is not an artifact, we carried out two calculations. First, to eliminate the possibility that it was simply a result of being trapped in a local minimum of the empirical energy surface, we built an initial SC-65369 structural model based on the crystal structure of GM-CSF in which loop $A B$ passes behind helix D. Simulated annealing was applied to this model using only unambiguously assigned long-range NOE constraints. At the completion of the simulated annealing procedure,
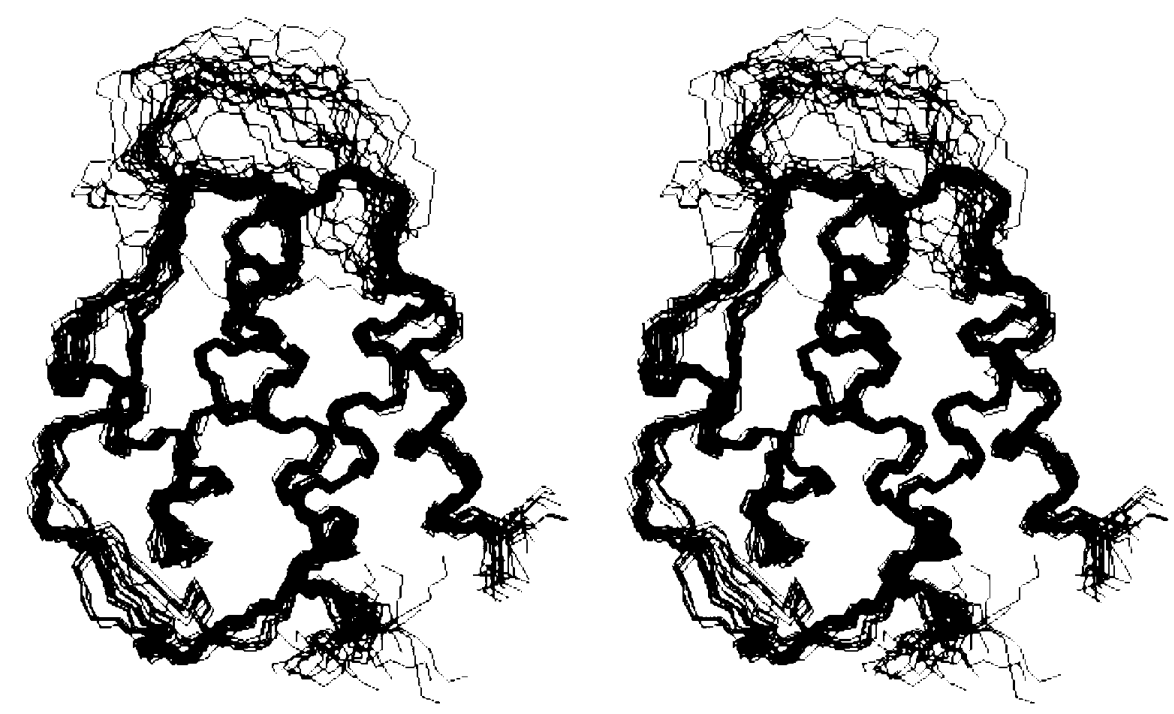

Figure 3. A stereo view of the superposition of $\left(\mathrm{N}, \mathrm{C}^{\alpha}, \mathrm{C}^{\prime}\right)$ of residues 14 to 27 and 40 to 125 of the 25 convergent structures; only the main-chain atoms are shown. The resultant r.m.s.d is $0.88( \pm 0.15) \AA$. The coordinates of the minimized average structure (PDB reference 1JLI) along with a list of constraints (PDB reference 1JLI-MR) used in the structure calculations have been deposited in the Brookhaven Protein Data Bank (PDB). 

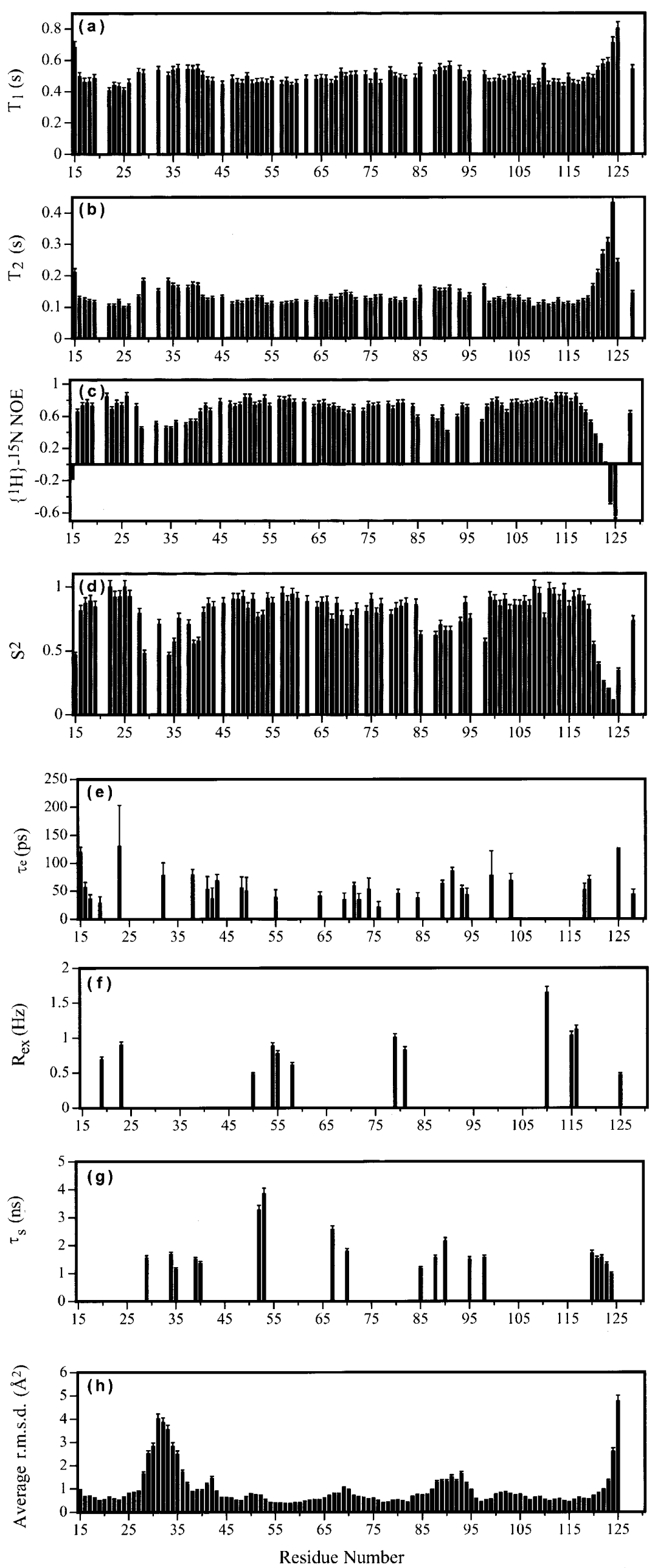

Figure 5. ${ }^{15} \mathrm{~N}$ relaxation behavior of SC-65369. (a) the observed ${ }^{15} \mathrm{~N} \mathrm{~T}_{1}$; (b) the observed ${ }^{15} \mathrm{~N} \mathrm{~T}_{2} ;(\mathrm{c}){ }^{15} \mathrm{~N}\left\{{ }^{1} \mathrm{H}\right\}$ NOE; (d) $S^{2}$; (e) $\tau_{\mathrm{e}}$; (f) $R_{\mathrm{ex}}$; (g) $\tau_{\mathrm{s}}$; and (h) average backbone atomic r.m.s.d. per residue. For residues that exhibit resolved chemical shift heterogeneity, the average relaxation parameters are plotted as described in the text. The side-chain indole nitrogen atom of Trp104 is plotted at residue position 128 . 
loop $\mathrm{AB}$ had moved to the front of helix $\mathrm{D}$, as had been observed in the converged structures. In order to eliminate the possibility that the loop AA' topology was the result of the misassignment of long-range NOEs, we excised the AA' segment (residues 28 to 39) from the starting model and carried out a second calculation in which a family of nine converged structures were generated using only the initial set of unambiguously assigned long-range NOE constraints. The resulting structures indicate that the position of helix $\mathrm{A}^{\prime}$ relative to the four-helical bundle is well conserved without the tethering effect from loop $\mathrm{AA}^{\prime}$, and that there would be severe steric conflict for this loop to connect helix $\mathrm{A}^{\prime}$ to helix A from behind helix D. Indeed, the NOEs from Ile99 to Ala64, Phe107 and Lys110; and those from Ile97 to Ala60 and Phe61 document the close contact between loop CD and helix $B$, as well as between loop $\mathrm{CD}$ and helix $\mathrm{D}$, and this close contact precludes a topology in which loop AA' could pass between loop CD and helix D.

\section{Backbone dynamics}

The ${ }^{15} \mathrm{~N} T_{1}, T_{2}$, and ${ }^{15} \mathrm{~N}\left\{{ }^{1} \mathrm{H}\right\}$ NOE relaxation parameters for 92 of 103 possible sites (including the indole nitrogen of Trp104; parameters determined and heterogeneous sites averaged as described in Materials and Methods) are plotted against residue number in Figure 5. For all backbone ${ }^{15} \mathrm{~N}$, the mean $T_{1} / T_{2}$ ratio was determined to be $3.76( \pm 0.54)$. When backbone amide nitrogen atoms that exhibit significant contributions from either internal motions or exchange processes (identified as having either an ${ }^{15} \mathrm{~N}\left\{{ }^{1} \mathrm{H}\right\}$ NOE $<0.65$ or a $T_{1} / T_{2}$ ratio more than one standard deviation from the mean) were excluded, the mean $T_{1} / T_{2}$ ratio of the subset (55 residues) became $3.91( \pm 0.23)$, from which a global molecular tumbling time $\left(\tau_{\mathrm{m}}\right)$ of $6.50( \pm 0.04)$ ns was estimated.

Using the global $\tau_{\mathrm{m}}$ determined as described above, all data were fitted to equations 1 to 3 in Clore et al. (1990) by optimizing the order parameters $S^{2}$ with $\tau_{\mathrm{e}}$ fixed at zero. The relaxation data for 30 residues could be fitted using $S^{2}$ alone to within $95 \%$ confidence limits, defined as all three calculated relaxation parameters falling within 1.96 times the experimental uncertainties. For residues that could not be fitted adequately with $S^{2}$ alone, both $S^{2}$ and $\tau_{\mathrm{e}}$ were optimized; an additional 27 residues could be fitted using this simple one-time-scale formalism. More sophisticated models were required for the remaining residues. When $R_{\text {ex }}$ was introduced as an additional parameter to $1 / T_{2}$, five residues were fit using $\left(S^{2}, R_{\mathrm{ex}}\right)$, and an additional four were fitted using $\left(S^{2}, \tau_{\mathrm{e}}, R_{\mathrm{ex}}\right)$. The extended two-time-scale formalism $\left(S_{\mathrm{f}}^{2}, S_{\mathrm{s}}^{2}, \tau_{\mathrm{s}}\right)$ was found necessary to fit 18 residues. The remaining eight residues exhibited deviations of $T_{1}, T_{2}$, or NOE between two and fourfold of the experimental uncertainties in all models tested. For these residues, the simplest models were

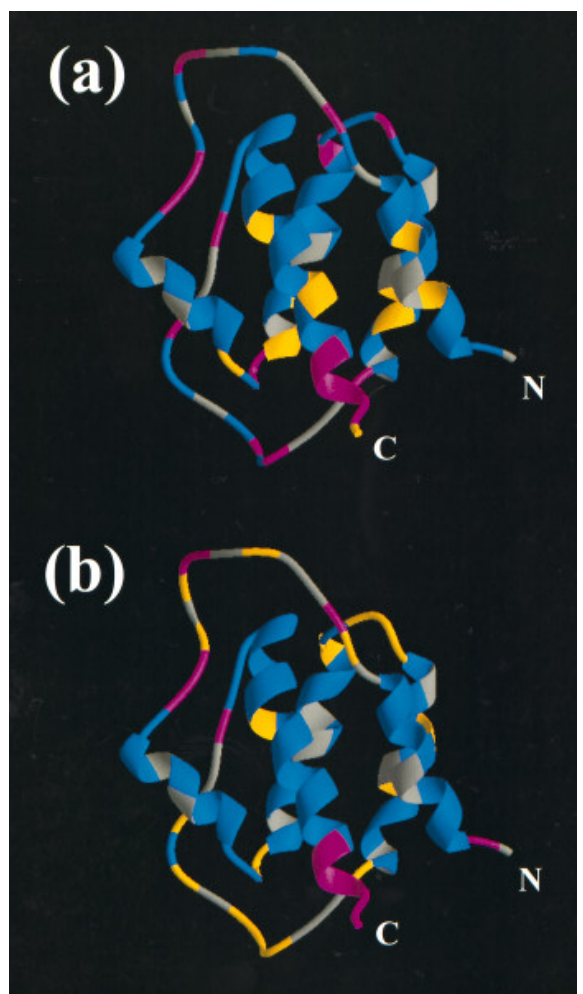

Figure 6. Illustration of the dynamics pattern on the ribbon diagram of the minimized average structure (RIBBONS; Carson, 1991). (a) Distribution of motional models used in the model-free analysis. Blue, $\left(S^{2}\right)$ or $\left(S^{2}, \tau_{\mathrm{e}}\right)$; gold, $\left(S^{2}, R_{\mathrm{ex}}\right)$ or $\left(S^{2}, \tau_{\mathrm{e}}, R_{\mathrm{ex}}\right)$; magenta, $\left(S_{\mathrm{s}}^{2}, S_{\mathrm{f}}^{2}, \tau_{\mathrm{s}}\right)$; gray, not measured; (b) Distribution of order parameters $S^{2}$. Blue, $0.8 \leqslant S^{2} \leqslant 1.0$; gold, $0.6 \leqslant S^{2} \leqslant 0.8$; magenta, $S^{2}<0.6$; gray, not measured.

chosen that gave the lowest $\chi^{2}$ with no more than two of the three relaxation parameters having significant deviation(s). The sufficiency levels of the models are similar to those observed for other globular proteins (cf. Redfield et al., 1992; Farrow et al., 1994). The isotropic motion assumption in the model-free formalism thus appears to be valid, even though the three principal components of the inertia tensor of SC-65369 have a ratio of 1.00:0.64:0.40. With an appropriate model determined for each residue, all model-free parameters, including the global tumbling time, were optimized simultaneously. The optimized $\tau_{\mathrm{m}}$ of $6.47( \pm 0.02) \mathrm{ns}$ is in good agreement with the initial guess of $6.50 \mathrm{~ns}$ derived from the $T_{1} / T_{2}$ ratio. The best-fit model-free parameters for individual residues are shown in Figure 5. The distributions of the models required to fit the data and the overall order parameter $S^{2}$ are color coded on a ribbon diagram of the average structure in Figure 6. It is interesting to note that many residues for which the two-time-scale model had to be invoked cluster sequentially. In contrast, residues that required $R_{\mathrm{ex}}$ to fit the relaxation data are scattered along the primary sequence, but appear to cluster spatially. 


\section{Discussion}

\section{The solution structure of SC-65369}

The structure of SC-65369 exhibits a characteristic up-up-down-down bundle of four amphipathic helices, with an additional fifth helix occurring at the end of the crossover loop $\mathrm{AB}$. As will be discussed below, the unexpected addition of helix $\mathrm{A}^{\prime}$ and the crossing of loop $\mathrm{AB}$ in front of helix $\mathrm{D}$ and loop CD is distinct from the other members of the short-chain cytokine family whose structures have been determined. Although the determination of this structure was complicated by the degeneracy in resonances that resulted from the high helical content, as well as by the chemical shift heterogeneity, the resulting structure is of good quality in terms of NOE constraint density and atomic r.m.s.d.

Although the solvent-inaccessible residues in SC-65369 (Figure 1(d)) are overwhelmingly hydrophobic, several residues with polar or charged functional groups are among those most highly buried in the interior of the structure, i.e. Asp44, Asn52, Arg54, Asn57, Glu106, Lys110, and Tyr114. Inspection of the structures indicates that the three charged residues, Asp44, Glu106, and Lys110 are close to one another and therefore may be involved in an electrostatic interaction. The closest distance between the Asp44 carboxyl oxygen atom (solventaccessible area (SA) $9( \pm 6) \AA^{2}$ ) and Lys110 $\mathrm{N}^{\zeta}$ (SA $\left.0.0( \pm 0.1) \AA^{2}\right)$ is $5.2( \pm 1.3) \AA$ in the family of 25 converged structures, while that between Glu106 carboxyl oxygen atoms (SA $0.4( \pm 1.0) \AA^{2}$ ) and Lys110 $\mathrm{N}^{\zeta}$ is $4.4( \pm 1.6) \AA$; when electrostatic energy was included in the minimization proceduret, the $\mathrm{N}-\mathrm{O}$ distances for Lys110-Asp44 and Lys110Glu106 became 3.2 and $2.6 \AA$, respectively. These distances suggest that a charge interaction could exist among these residues. For many other buried polar residues, interior hydrogen bonds are implicated, but were not included as explicit hydrogen-bond constraints in the structure calculations. The side-chain nitrogen atom of Asn52 (SA $\left.1.1( \pm 1.5) \AA^{2}\right)$ is in the vicinity of the backbone carbonyl oxygen atom of Ala91 $\left(\left\langle d_{\mathrm{NO}}\right\rangle=\right.$ $\left.\left.3.7( \pm 1.2) \AA ̊ ; A_{\mathrm{N}-\mathrm{NH}-\mathrm{O}}\right\rangle=87( \pm 23)^{\circ}\right)$, while the sidechain carbonyl oxygen atom of Asn52 (SA $8.1( \pm 14.4) \AA)$ is positioned for hydrogen bonding with the amide $\mathrm{NH}$ of both Thr89 $\left(\left\langle d_{\mathrm{NO}}\right\rangle=\right.$ $\left.3.9( \pm 1.0) \AA ;\left\langle A_{\mathrm{N}-\mathrm{NH}-\mathrm{O}}\right\rangle=101( \pm 49)^{\circ}\right)$ and Ala91 $\left(\left\langle d_{\mathrm{NO}}\right\rangle=4.1( \pm 0.9) \AA ;\left\langle A_{\mathrm{N}-\mathrm{NH}-\mathrm{O}}\right\rangle=145( \pm 18)^{\circ}\right)$. The amide hydrogen atom of Ala91 is mildly resistant to exchange with deuterons (Feng et al., 1995), supporting the existence of a hydrogen bond. For Asn57, the side-chain nitrogen atom (SA $\left.0.0( \pm 0.0) \AA^{2}\right)$ is positioned to donate a hydrogen

t Superposition of the backbone $\left(\mathrm{N}, \mathrm{C}^{\alpha}, \mathrm{C}^{\prime}\right)$ of the average structure minimized with and without an electrostatic term in the energy function gave an r.m.s.d. of $0.16 \AA$, thus indicating that including the electrostatics has a minimal effect on the overall structure.

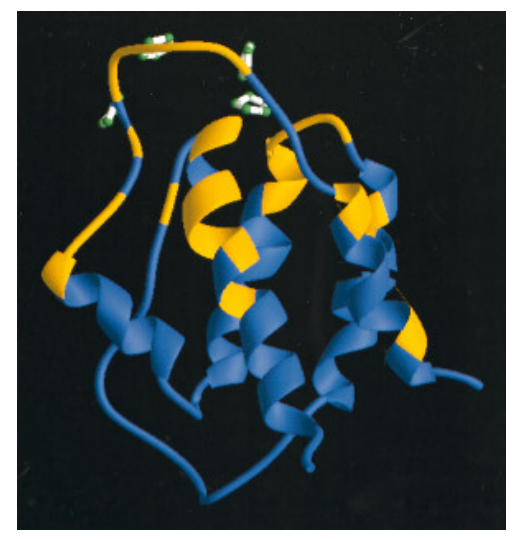

Figure 7. Ribbon diagram of the minimized average structure of SC-65369 with heterogeneous sites illustrated in gold. The four proline residues in the AA' loop are shown with a ball-and-stick representation. Illustration generated using RIBBONS (Carson, 1991).

bond with both the backbone carbonyl oxygen atom of Ile47 $\left(\left\langle d_{\mathrm{NO}}\right\rangle=3.8( \pm 0.7) \AA ;\left\langle A_{\mathrm{N}-\mathrm{NH}-\mathrm{O}}\right\rangle=\right.$ $\left.130( \pm 10)^{\circ}\right)$ and that of Leu53 $\left(\left\langle d_{\mathrm{NO}}\right\rangle=\right.$ 2.7 $\left.( \pm 0.2) \AA ; \quad\left\langle A_{\mathrm{N}-\mathrm{NH}-\mathrm{O}}\right\rangle=91( \pm 11)^{\circ}\right)$. The guanidino NHs of Arg54 (SA 0.1 $( \pm 0.2) \AA^{2}$ and $\left.0.0( \pm 0.0) \AA^{2}\right)$ may form hydrogen bonds to the backbone carbonyl oxygen atom of Met49 $\left(\left\langle d_{\mathrm{NO}}\right\rangle=4.5( \pm 1.9) \AA ; \quad\left\langle A_{\mathrm{N}-\mathrm{NH}-\mathrm{O}}\right\rangle=89( \pm 43)^{\circ}\right)$ and that of Leu48 $\left(\left\langle d_{\mathrm{NO}}\right\rangle=3.9( \pm 1.3) \AA ;\left\langle A_{\mathrm{N}-\mathrm{NH}-\mathrm{O}}\right\rangle=\right.$ $\left.101( \pm 34)^{\circ}\right)$, respectively. Although completely buried inside the protein, the side-chain hydroxyl group of Tyr114 (SA $0.0( \pm 0.0) \AA^{2}$ ) appears to be distant from any possible hydrogen bonding partners. Inspection of the packing around the Tyr114 ring indicates that it is rather loose, and averaged chemical shifts were observed for the aromatic 2,4- and 3,5-H resonances. The observation of a void adjacent to the Tyr114 aromatic ring is consistent with mutagenesis studies in which substitution of Tyr114 by Trp, which has a larger side-chain with the potential to disturb close packing, nevertheless retained essentially full activity (Olins et al., 1995). It is possible that the void in the vicinity of the Tyr114 aromatic ring could accommodate an internal water molecule(s) in order to satisfy the hydrogen bonding requirements of the buried hydroxyl group. Interestingly, many of the above buried residues are either evolutionarily conserved or were found to be intolerant of substitutions (Olins et al., 1995).

In a previous report (Feng et al., 1995), we suggested that the origin of the chemical shift heterogeneity might be proline isomerization in the proline-rich loop AA'. The current structure lends further support to the hypothesis. Figure 7 illustrates a ribbon diagram of the average structure of SC-65369 with residues that exhibit chemical shift heterogeneity highlighted in yellow. It is striking that the majority of these residues are located in proximity to loop AA', which contains four proline residues whose peptide bond configurations could 
not be determined with NOE information (Feng et al., 1995).

\section{Backbone dynamics of SC-65369}

In addition to the three-dimensional structure, the dynamic behavior of SC-65369 was explored by measuring ${ }^{15} \mathrm{~N}$ relaxation parameters. The global tumbling time of $6.47( \pm 0.02) \mathrm{ns}$ determined for SC-65369 is consistent with the protein being a monomer in solution, and is in proper relation to its size when compared to results obtained with other proteins of various sizes (e.g. Schneider et al., 1992; Kay et al., 1989; Stone et al., 1992; Kördel et al., 1992; Palmer et al., 1991; Clore et al., 1990). Figure 5 summarizes the results of the model-free analysis as implemented by Palmer et al. (1991). It can be seen from the order parameters $S^{2}$, which represents the degree of spatial restriction of backbone motion, that the SC-65369 structure is overall relatively rigid, with the exceptions of loop $\mathrm{AA}^{\prime}$ (residues 29 to 40 ; average $S^{2}=0.60$ ), loop CD (residues 85 to 98; average $S^{2}=0.69$ ), and the C-terminal regions (residues 120 to 125; average $S^{2}=0.30$ ). In contrast to the $C$ terminus, the $\mathrm{N}$-terminal segment has values of $S^{2}>0.80$, except for the first measurable residue in the sequence $\left(S^{2}=0.47\right)$; this rigidity may be attributed to the disulfide bond between Cys16 and Cys84. This pattern correlates well with the average backbone atomic r.m.s.d. plotted in Figure 5(h), and further suggests that the dynamic behavior is responsible for the absence of long-range NOEs found in loop $\mathrm{AA}^{\prime}$ and at the $\mathrm{C}$ terminus. The helical regions gave average $S^{2}$ values of 0.91 (helix A), 0.88 (helix A'), 0.88 (helix B), 0.84 (helix C), and 0.90 (helix D; residues 104 to 119 only), respectively. The large $S^{2}$ found in helix $\mathrm{A}^{\prime}$ indicates that it is an integral part of the structural framework.

Extension of the model-free approach (Clore et al., 1990) allows the analysis of motions on two different time scales. One corresponds to fast motions that occur on the picosecond to nanosecond time scale $\left(\tau_{\mathrm{e}}\right.$ and $\left.\tau_{\mathrm{s}}\right)$, and the other accounts for slow motions on the microsecond to millisecond time scale $\left(R_{\text {ex }}\right)$. Although two conformations of SC65369 appear to coexist in solution, the exchange between the two conformers is slow and appears to be beyond the range that can be detected in the current dynamics studies. Although the origin of $R_{\mathrm{ex}}$ may arise from many sources, and is often difficult to assign, residues in SC-65369 that exhibited a significant contribution from exchange (range 0.5 to $2.0 \mathrm{~Hz}$ ) appear to localize in the vicinity of aromatic rings (Figure 6(a)): residues 19, 23, 54, 55, 79, and 81 are located in the proximity of Tyr114; residues 58 and 110 are located in the neighborhood of Phe61; residue 110 is also near Phe107; residue 115 is close to Phe113. All these aromatic rings exhibit average chemical shifts. Such a correlation between residues requiring the $R_{\mathrm{ex}}$ term and the proximity to aromatic rings has been noted previously (cf. Constantine et al., 1993; Farrow et al., 1994). Residues in
SC-65369 that required the two-time-scale model in order to adequately fit are localized either in the inter-helical connections (loop AA'; $\tau_{\mathrm{s}}=1$ to $2 \mathrm{~ns}$; turn $\mathrm{A}^{\prime} \mathrm{B}: \tau_{\mathrm{s}}=3$ to $4 \mathrm{~ns}$; loop BC: $\tau_{\mathrm{s}}=1$ to $2 \mathrm{~ns}$; loop CD: $\tau_{s}=1$ to $\left.2 \mathrm{~ns}\right)$ or at the $C$ terminus ( $\tau_{\mathrm{s}}=1$ to $2 \mathrm{~ns}$ ) (Figures $5(\mathrm{~g})$ and $6(\mathrm{~b})$ ).

These results are qualitatively similar to the pattern observed for IL-4 (Redfield et al., 1992) and G-CSF (Zink et al., 1994), both of which provided evidence for increased motional flexibility in the loops relative to the amphipathic helices. The average $S^{2}$ of 0.88 observed in helical regions of SC-65369 is comparable to $S^{2}=0.9$ and $S^{2}=0.84$ found in helical regions of IL-4 and G-CSF, respectively. However, unlike G-CSF, wherein many residues required the term $R_{\mathrm{ex}}$ to adequately fit the relaxation data, $R_{\mathrm{ex}}$ was necessary for only a small number of residues in SC-65369. It was observed in IL-4 that many of the residues with a significant exchange contribution are located near the disulfide bridges, while no such phenomenon was observed in SC-65369. The residues that exhibit slow internal motions in IL-4 (ns scale, two-time-scale model) reside in loop regions or near the termini, similar to the locations found in SC-65369. Although $B$-factors in crystal structures may be influenced by the external effect of crystal packing forces, it is interesting to note that in both GM-CSF (Diederichs et al., 1991) and IL-5 (Milburn et al., 1993), loop AB exhibits the highest average $B$-factors outside of the terminal regions, similar to the atomic r.m.s.d. pattern seen in SC-65369.

\section{The relationship between hIL-3 and SC-65369}

Several lines of evidence indicate that the structural features of SC-65369 are relevant for wild-type hIL-3. First, SC-65369 is fully active in both cell proliferation assays (P. Olins \& C. Bauer, unpublished results) and in binding to the low affinity IL-3 receptor (J. Thomas, unpublished results). Similar helical contents were determined for SC-65369 and hIL-3 using far-UV CD spectroscopy at pH 3 (Freeman et al., 1991; R. Schilling, unpublished results), which is also consistent with the nearly identical secondary structural predictions for these two sequences (Y. Feng, unpublished results). Further evidence comes from epitope mapping with anti-IL-3 monoclonal antibodies. Kaushansky and co-workers have shown that antibodies which recognize residues 21 to 45 and residues 107 to 119 could not bind to hIL-3 simultaneously, suggesting that these two regions were in close juxtaposition in the structure (Kaushansky et al., 1992). Examination of the structure of SC-65369 reveals that these two sequences, corresponding to helix A-helix $\mathrm{A}^{\prime}$ and helix $\mathrm{D}$, are indeed adjacent to one another (see Figure 4). Finally, an analysis of the locations of the sites of substitution indicates that they are highly segregated to the surface: V14A $\left(160 \AA^{2}\right)$ is the N-terminal residue; N18I $\left(92 \AA^{2}\right)$ is separated from $\mathrm{T} 25 \mathrm{H}\left(149 \AA^{2}\right)$ by two turns on the hydrophilic face 
of helix A; Q29R (208 $\left.\AA^{2}\right)$, L32N (105 $\left.\AA^{2}\right)$, and F37P $\left(88 \AA^{2}\right)$ are in loop $\mathrm{AA}^{\prime}$ and are well-exposed with no long-range NOEs; G42S $\left(87 \AA^{2}\right)$ and Q45M $\left(99 \AA^{2}\right)$ are in helix $A^{\prime}$, N51R $\left(125 \AA^{2}\right)$ is in the first position of the type I turn between helices $A^{\prime}$ and B; R55T (33 $\left.\AA^{2}\right)$, E591 $\left(111 \AA^{2}\right)$ and N62V $\left(23 \AA^{2}\right)$ are on helix B; and S67H $\left(145 \AA^{2}\right)$ and Q69E $\left(159 \AA^{2}\right)$ are part of the reversal in chain direction between helices B and C. Only R55T and N62V are somewhat buried. Despite the large number of substitutions, the hydrophobic interior has been preserved. The retention of biological activity and similar helical contents make it unlikely that the overall conformation of these proteins could differ substantially, and the localization of the mutations on the surface would make it easier to accommodate such a large number of substitutions without grossly altering the fold. It is interesting that the recently reported crystal structure of an affinitymaturated mutant of $\mathrm{hGH}$, which had a similar number of substitutions distributed throughout the sequence, showed that most of the structure remains unchanged when compared with the wild-type protein in the receptor-bound state (Ultsch et al., 1994). Thus, it is plausible that SC-65369 could have a similar degree and kind of structural alteration.

Compared to native hIL-3, SC-65369 is missing the first 13 residues at the $\mathrm{N}$ terminus and the last eight residues at the $C$ terminus. Circular dichroism spectroscopy and secondary structural predictions suggest that these $\mathrm{N}$ and $\mathrm{C}$-terminal additions adopt extended conformations rather than extending the length of either helix A or helix D (Freeman et al., 1991). The fact that SC-65369 retains full activity suggests that whatever structure these missing residues might adopt, it is not important for growth promoting activity. Similar observations have been made for other truncation variants (Olins et al., 1995; Thomas et al., 1995; P. Olins \& C. Bauer, unpublished results) which were actually shown to have a modest increase in activity (Olins et al., 1995), which further argues against these residues being required for recognition and signal transduction.

hIL-3 has two consensus Asn-X-Thr/Ser sites that are potentially glycosylated, viz. Asn15-Cys16Thr17 and Asn70-Ala71-Ser72. Like many N-glycosylation sites in proteins, Asn70 occurs in a chain reversal, occupying the $i+3$ position of the type II turn occurring at residues 68 to 71 . Covalent modification by $\mathrm{N}$-linked carbohydrate at this solvent exposed site is unlikely to substantially alter the conformation.

\section{Comparison of the four-helical bundles of SC-65369, GM-CSF and IL-5}

At the outset of this study, published sequence alignments predicted that IL-3 is a short-chain cytokine that is most closely related to GM-CSF and IL-5 (Rozwarski et al., 1994), which share a common $\beta$-subunit of the high affinity receptor with IL-3 (Kitamura et al., 1991; Tavernier et al., 1991). Both the
GM-CSF and IL-5 structures have been solved using crystallographic methods (Diederichs et al., 1991; Walter et al., 1992; Milburn et al., 1993). GM-CSF is folded into the same up-up-down-down arrangement of the four helices as described here for SC-65369. Indeed, the two structures can be superimposed to $1.71 \AA$ when $62 \mathrm{C}^{\alpha}$ atoms in the four-helical bundle core are considered (Figure 8(a)). As discussed in detail below, however, a key difference in the hIL-3 fold is the arrangement and conformation of the loops that connect helix A to $B$ and helix C to D. IL- 5 exists as a dimer that has been described as a head-to-head pair of interdigitated four-helix bundles composed of three Nterminal helices from one chain and a single C-terminal helix from the other chain (Milburn et al., 1993). The topology of each IL-5 four-helix bundle is thus quite similar to GM-CSF with the exception that loop CD and helix D is contributed by the other polypeptide chain. Using a composite monomer of the four-helical bundle structural domain of IL-5, a high degree of structural similarity is evident between SC-65369 and IL- 5 by superimposing 58 equivalent $\mathrm{C}^{\alpha}$ atoms with a resultant r.m.s.d. of $1.96 \AA$ (Figure 8(a)). Based on the optimal superposition of the helical bundles, the proposed sequence alignment of the helical regions (Rozwarski et al., 1994) is revised as shown in Figure 8(b). Nearly all conserved residues among the three proteins, such as Leu27, Leu78, and Leu111 (IL-3 numbering), are buried in a conserved core, which is likely to be important for structural integrity. Only Glu22 is largely exposed to the solvent, and mutagenesis studies indicate that this residue is likely to be important for interacting with the common $\beta$-subunit of the high affinity receptor (Lopez et al., 1992b; B. K. Klein, unpublished results).

\section{The loop $A B$ crossover and classification of helical cytokines}

Despite the remarkable diversity in primary sequences, all members of the hematopoietic growth factor family whose structures are known to date display the common up-up-down-down lefthanded four-helix bundle topology. In a recent paper, Karplus and co-workers (Rozwarski et al., 1994) modified and extended the original taxonomic classification of four $\alpha$-helical bundle cytokines into three subfamilies: the short-chain cytokines (known structures GM-CSF, IL-5, IL-2, IL-4, and M-CSF); the long-chain cytokines (known structures GH, G-CSF and LIF); and the interferon-like cytokines (known structures interferon- $\beta$, interferon- $\gamma$ and IL-10). The short-chain cytokines are typified by (1) sequences of 105 to 145 residues, (2) short helices of 10 to 15 residues, (3) $\Omega$ of 30 to $40^{\circ}$ between the antiparallel pairs of helices (i.e. A-C and B-D), and (4) a loop $A B$ that passes behind helix $D$ and then under loop $\mathrm{CD}$ before forming a short two-stranded antiparallel $\beta$-sheet with loop $\mathrm{CD}$. In contrast, the long-chain cytokine bundles are recognized as 


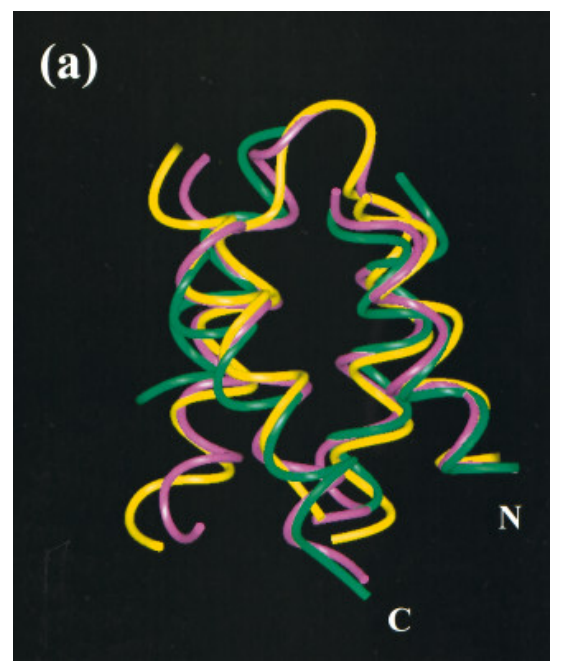

(b)

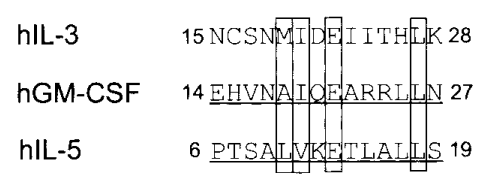

HELIX C

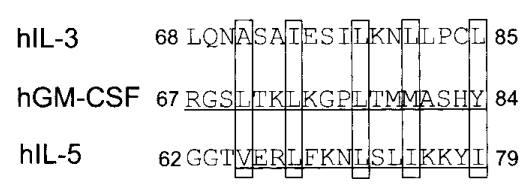

HELIX B

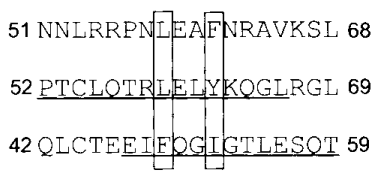

HELIX D

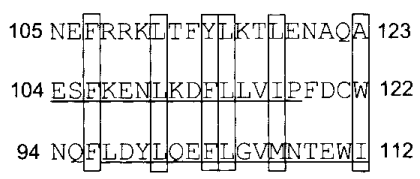

Figure 8. (a) Superposition of the four-helical core of GM-CSF (yellow), SC-65369 (magenta), and IL-5 (green); only ribbons for residues 14 to 27,52 to 84 , and 104 to 118 of GM-CSF; residues 15 to 28,51 to 85 , and 105 to 123 of SC-65369; and residues 6 to 19,47 to 59,65 to 79 of the first chain, and 97 to 112 of the second chain of IL-5 are displayed. The r.m.s.d. is $1.71 \AA$ between GM-CSF and SC-65369 $\left(62 \mathrm{C}^{\alpha}\right.$ atoms: residues 15 to 28,51 to 65,68 to 85 , and 105 to 119 in SC-65369; and residues 14 to 27,52 to 66,67 to 84 , and 104 to 118 in GM-CSF), and $1.96 \AA$ between IL-5 and SC-65369 (59 $\mathrm{C}^{\alpha}$ atoms: residues 15 to 28,56 to 68,71 to 85 , and 108 to 123 in SC-65369; and residues 6 to 19,47 to 59,65 to 79 of the first chain, and 97 to 112 of the second chain of IL-5). (b) Structure-based sequence alignment of SC-65369 with GM-CSF and IL-5. The amino acid residues used for the superpositions illustrated in (a) are underlined for GM-CSF and IL-5. Conserved and conservatively substituted residues are shown in boxes. In SC-65369, these residues have the following solvent accessible areas: M19, $54 \AA^{2}$; I20, $0.6 \AA^{2}$; E22, $103 \AA^{2} ; \mathrm{L} 27,5 \AA^{2} ; \mathrm{L} 58,0.0 \AA^{2} ; \mathrm{F} 61$, $0.2 \AA^{2} ; \mathrm{A} 71,0.4 \AA^{2} ; \mathrm{I74}, 19 \AA^{2} ; \mathrm{L} 78$, $1.7 \AA^{2} ; \mathrm{L} 81,0.0 \AA^{2} ; \mathrm{L} 85,13 \AA^{2} ; \mathrm{F} 107$, $3 \AA^{2}$; L111， $0.2 \AA^{2}$; Y114, $0.0 \AA^{2}$, L115, $0.0 \AA^{2}$; L118, $2 \AA^{2}$; A123, $79 \AA^{2}$. having (1) longer sequences (160 to 200 residues), (2) longer helices (ca 25 residues), (3) a smaller angle between the A-C and B-D pairs $\left(<20^{\circ}\right)$, and (4) $\alpha$-helices in overhand loops, and a loop $\mathrm{AB}$ that crosses in front of helix $\mathrm{D}$ and which remains in front of loop CD. The interferon-subfamily has (1) helix packing angles similar to the short-chain cytokines, (2) a loop AB crossover similar to the long-chain family and (3) a long "up" helix in loop CD which forms part of the core structure.

Distinct differences between the structures of SC-65369, GM-CSF and IL-5 lie in the secondary structure and arrangement of the two crossover segments, loops $\mathrm{AB}$ and $\mathrm{CD}$. In both GM-CSF and IL-5, short stretches of $\beta$-sheet occur between adjacent stretches of loops $\mathrm{AB}$ and $\mathrm{CD}$, whereas in SC-65369 a short helix resides in loop AB (residues 42 to 49; helix A') and an irregular structure exists in loop CD. We note that GM-CSF does have approximately one turn of $3_{10}$-helix in loop $\mathrm{AB}$ (residues 33 to 36; Diederichs et al., 1991), but that this occurs immediately after helix A, and hence places it at the top of the helical bundle distal to the chain termini, whereas helix $\mathrm{A}^{\prime}$ in the hIL-3 variant is at the end of loop $\mathrm{AB}$ and is on the side of the bundle adjacent to helix D (Figure 9). A second significant difference is the position of the $A B$ segment relative to the $C D$ loop and helix $D$. The $A B$ loop in GM-CSF penetrates the space between loop $\mathrm{CD}$ and helix $\mathrm{D}$ in what has been described as a "threaded" topology (Diederichs et al., 1991). Although less obvious in IL-5 due to the novel dimer arrangement, the position of its $\mathrm{AB}$ loop is

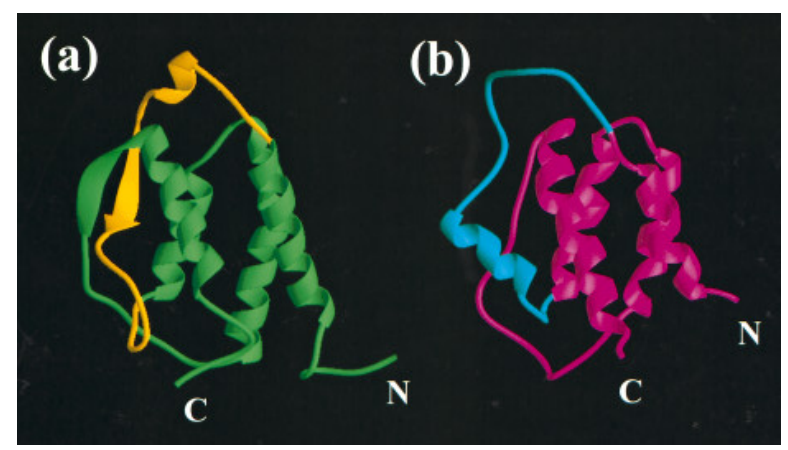

Figure 9. Ribbon representations of (a) GM-CSF and (b) SC-65369 with the differences in the AB loop conformation highlighted in gold and cyan, respectively. Illustration generated using RIBBONS (Carson, 1991). 
similar to that of GM-CSF. In the structure of SC-65369, the AA' loop resides in front of the N-terminal half of helix D. Clearly, the IL-3 fold suggests a need to re-examine the defining features of the consensus structure for the short-chain cytokines (Rozwarski et al., 1994). Rather than resembling the other short-chain cytokines, the SC-65369 crossover has features of the long-chain family in terms of the relative position of the $A B$ and $C D$ loops, and features of the interferon-like family in terms of having a structurally integrated helix. However, there are distinct differences between SC-65369 and either the long-chain family or the interferon-like family. Whereas helix $\mathrm{A}^{\prime}$ appears to be an integral part of the SC-65369 core structure on the basis of its low atomic r.m.s.d., rigidity as indicated in ${ }^{15} \mathrm{~N}$ dynamics studies, and the surface area buried by helix $\mathrm{D}$ and loop $\mathrm{CD}$, the mini-helices observed in the $\mathrm{AB}$ loop of hGH (de Vos et al., 1992; Ultsch et al., 1994) are not tightly packed to the four-helix bundle and display a higher degree of mobility than the helical core. Similar situations exist for the short helices in G-CSF (Hill et al., 1993; Lovejoy et al., 1993; Zink et al., 1992, 1994; Werner et al., 1994) and LIF (Robinson et al., 1994). The absence of any helix in loop CD in SC-65369 distinguishes it from the interferons. It is interesting to note that a "nascent" helix was observed in loop $\mathrm{AB}$ immediately preceding helix $\mathrm{B}$ in IL-4 (Smith et al., 1992; Redfield et al., 1992), where helix A' resides in SC-65369. The nascent helix displayed NOEs characteristic of a helical conformation, but the ${ }^{3} J_{\mathrm{NH} \alpha}$ coupling constants were inconsistent with helical structure.

The determination of whether IL-3 is the only exception to the rule for $A B$ crossovers in short-chain cytokines must wait for other shortchain cytokine structures to emerge. Most comparative studies of affinity and selectivity to date have focussed on differences in the surface residues of helices $\mathrm{A}$ and $\mathrm{D}$, and have tended to rely on interpretations borrowed from the structure of the GH-GHR complex (Metcalf \& Nicola, 1995). The functional importance of the $\mathrm{AB}$ loop and the mini-helix in the $\mathrm{AB}$ loop of cytokines has also been described for the GH-GHR and GH-PRLR complexes (de Vos et al., 1992; Somers et al., 1994). While residues within helices $\mathrm{A}$ and D clearly play a role in receptor interaction, the observed differences between the structural features of these loops among GM-CSF, IL-5 and the IL-3 variants suggests that these regions are likely to be important for the observed specificity of the corresponding receptor $\alpha$-subunits. Extensive mutagenesis studies to be described elsewhere support this hypothesis (B. K. Klein, unpublished results).

\section{Materials and Methods}

\section{Interproton distance and dihedral angle constraints}

SC-65369 (P. Olins and C. Bauer, unpublished results) is a recombinant protein consisting of residues 14 to 125 of wild-type hIL-3 (Yang et al., 1986) with amino acid substitutions at 14 of 112 positions: V14A, N18I, T25H, Q29R, 132N, F37P, G42S, Q45M, N51R, R55T, E59L, N62V, $\mathrm{S} 67 \mathrm{H}$, and Q69E. (U-15 $\mathrm{N}$ )-labeled and $\left(\mathrm{U}-{ }^{15} \mathrm{~N},{ }^{13} \mathrm{C}\right)$-doublelabeled SC-65369 samples were prepared and characterized as described in a previous study (Feng et al., 1995). The interproton distance constraints were derived using the resonance assignments reported previously (Feng et al., 1995) and NOEs determined at $\mathrm{pH} 4.6$ and $30^{\circ} \mathrm{C}$ from a 3D simultaneously ${ }^{13} \mathrm{C}_{1}^{15} \mathrm{~N}$-edited NOESY-HSQC spectrum (Pascal et al., 1994) recorded on a double-labeled sample with a mixing time of $130 \mathrm{~ms}$ and a $3 \mathrm{D}{ }^{1} \mathrm{H}^{15} \mathrm{~N}$ HMQC-NOESY-HMQC spectrum (Ikura et al., 1990) recorded on an ${ }^{15} \mathrm{~N}$-labeled sample with a mixing time of $140 \mathrm{~ms}$. Ambiguity in the assignment of some long-range NOEs was eliminated by consulting either an ${ }^{15} \mathrm{~N}$-edited NOESY-HMQC spectrum (Marion et al., 1989; Zuiderweg \& Fesik, 1989) of an ${ }^{15} \mathrm{~N}$-labeled sample in $\mathrm{H}_{2} \mathrm{O}$ or a ${ }^{13} \mathrm{C}$-edited NOESY-HMQC spectrum (Ikura et al., 1990) of a double-labeled sample in ${ }^{2} \mathrm{H}_{2} \mathrm{O}$. The acquisition and processing details for these experiments were given by Feng et al. (1995). The backbone ${ }^{3} J_{\mathrm{NH}} \alpha$ coupling constants extracted from a 2D ${ }^{1} \mathrm{H}^{-15} \mathrm{~N}$ HMQC-J spectrum (Kay \& Bax, 1990; Forman-Kay et al., 1990) were also reported earlier (Feng et al., 1995). A 3D simultaneously ${ }^{13} \mathrm{C},{ }_{1}^{15} \mathrm{~N}$-edited ROESY-HSQC spectrum was recorded using similar acquisition parameters as for the corresponding NOESY-HSQC experiment in order to confirm that certain cross-peaks were due to cross-relaxation and not to chemical or conformational exchange.

\section{${ }^{15} \mathrm{~N}$ relaxation measurements}

${ }^{15} \mathrm{~N}-{ }^{1} \mathrm{H}$ HSQC-type experiments for ${ }^{15} \mathrm{~N} T_{1}, T_{2}$, and ${ }^{15} \mathrm{~N}$ $\left\{{ }^{1} \mathrm{H}\right\}$ NOE measurements were collected on an ${ }^{15} \mathrm{~N}$ labeled SC-65369 sample at $30^{\circ} \mathrm{C}$ on a triple-resonance Varian Unity $500-\mathrm{MHz}$ spectrometer equipped with a pulsed-field gradient unit and a 5-mm triple-tuned probe using pulse sequences described by Farrow et al. (1994). In order to minimize solvent saturation, the spin-lock pulses were replaced by selective pulses that keep the $\mathrm{H}_{2} \mathrm{O}$ signal along the $z$-axis (Kay et al., 1994). Solvent suppression was achieved by using gradient pulses and all relaxation experiments employed the enhanced sensitivity method (Kay et al., 1992). ${ }^{15} \mathrm{~N} T_{1}$ values were determined from 12 spectra with $T_{1}$ delays of 22, 56, 100, $178,255,366,466,555,699,888,1110$, and $1380 \mathrm{~ms}$. Similarly, ${ }^{15} \mathrm{~N} T_{2}$ parameters were extracted from 11 spectra collected with $T_{2}$ delays of $17,34,50,67,84,101$, $118,134,151,168$, and $185 \mathrm{~ms}$. The delays between scans were 1.5 seconds in the $T_{1}$ experiments and 1.7 seconds in the $T_{2}$ experiments. In the experiment recorded in the presence of ${ }^{15} \mathrm{~N}\left\{{ }^{1} \mathrm{H}\right\}$ NOEs, protons were saturated for three seconds, while the reference experiment employed a compensating delay of three seconds. The spectra were recorded with spectral widths of $6400 \mathrm{~Hz}\left(F_{2}:{ }^{1} \mathrm{H}\right)$ and $1265 \mathrm{~Hz}\left(F_{1}:{ }^{15} \mathrm{~N}\right)$ using $1024 \times 100$ complex matrices for $T_{1}$ spectra, $1024 \times 95$ complex matrices for $T_{2}$ spectra, and $1024 \times 80$ complex matrices for NOE spectra. Pure absorptive line shapes were obtained as described by Kay et al. (1992), and all spectra were processed using Triad (Tripos Associates, St Louis, MO) on Sun or Silicon Graphics workstations. Data in the $F_{1}$ dimension were extended to 200 complex points for $T_{1}$ data, 190 complex points for $T_{2}$ data, and 160 complex points for NOE data using the mirror-image linear prediction routine implemented in Triad and then zero-filled to 512 points. Cosine and Gaussian window functions were applied 
along $F_{1}$ and $F_{2}$, respectively, and the final size for each spectrum was $1024 \times 512$ real points.

\section{Structure calculations}

Inter-proton NOEs were identified using previously published assignments through an iterative process. Several phases of structure calculations were carried out, starting with a preliminary phase in which only unambiguous long-range NOE constraints were included in order to generate an initial model, which was then used to resolve remaining ambiguities in the long-range NOE assignments. Subsequent phases, which eventually included the full set of constraints, were used to refine the final structures presented in this paper. The NOE intensities were classified into strong, medium, weak, or very weak, corresponding to distance bounds of 1.8 to 2.7, 1.8 to $3.5,1.8$ to 5.0 , and 1.8 to $6.0 \AA$, respectively. The initial cutoffs were based on the intensities of cross-peaks between $\mathrm{NH}(i)-\mathrm{NH}(i+1)$ and $\mathrm{C}^{\alpha} \mathrm{H}(i)-\mathrm{NH}(i+3)$ in helical stretches and these cutoffs were empirically refined at a later stage. Currently, no stereospecific assignments are available for the methylene protons or methyl groups of Leu and Val, and so the pseudoatom correction was applied to constraints involving these protons (Wüthrich, 1986). In addition, upper bounds for distances involving methyl groups and aromatic ring protons were increased by $0.5 \AA$ (Clore \& Gronenborn, 1987). The single disulfide cross-link between Cys16 and Cys84 was explicitly introduced by constraining the $S_{16}-S_{84}$ distance and the bond angles formed by $C_{16}^{\beta}-S_{16}$ and $S_{16}-S_{84}$, and by $S_{16}-S_{84}$ and $S_{84}-C_{84}^{\beta}$. Constraints on the backbone dihedral angle $\phi$ were derived from the $3^{3} \int_{\mathrm{NH} \alpha}$ coupling constants, and were used according to the Karplus relationship whenever the measured ${ }^{3} J_{\mathrm{NH}}$ were less than $6 \mathrm{~Hz}$ or greater than $8 \mathrm{~Hz}$. For residues in helical stretches and turns with measurable ${ }^{3} J_{\mathrm{NH} \alpha}$, the angular values defined by the Karplus relationship were used with a range of $\pm 30^{\circ}$. For residues in helical stretches with unresolved ${ }^{3} \int_{\mathrm{NH} \alpha}$ (estimated $<5 \mathrm{~Hz}$ ), the lower and upper limits corresponded to $-66^{\circ}$ and $0^{\circ}$, respectively. For residues with ${ }^{3} J_{\mathrm{NH} \alpha}>8 \mathrm{~Hz}$, $\phi=-150^{\circ}$ to $-90^{\circ}$ were used as constraints. For other residues with ${ }^{3} J_{\mathrm{NH} \alpha}<6 \mathrm{~Hz}$, the range was restricted to $-180^{\circ}$ and $0^{\circ}$.

Hydrogen bond constraints were explicitly introduced on the basis of protection against solvent exchange, the presence of appropriate NOEs (e.g. $\mathrm{C}^{\alpha} \mathrm{H}(i)-\mathrm{NH}(i+4)$ in helical regions) and the following iterative process, essentially as described by Kraulis et al. (1989). An initial set of 13 hydrogen bonds in either helical or turn conformations was assigned based on NOE connectivity patterns. A family of preliminary structures, each with not more than one NOE violation greater than $0.5 \AA$, was then used to assign hydrogen bonds. Both the distance between the amide nitrogen atom and the carbonyl oxygen atom $\left(d_{\mathrm{NO}}\right)$ and the angle formed by the amide nitrogen atom, amide hydrogen atom and carbonyl oxygen atom $\left(A_{\mathrm{N}-\mathrm{HN}-\mathrm{O}}\right)$ were considered. For a hydrogen bond to be assigned, the average $d_{\mathrm{NO}}\left(\left\langle d_{\mathrm{NO}}\right\rangle\right)$ must not be greater than $3.3 \AA,\left\langle d_{\mathrm{NO}}\right\rangle$ plus one standard deviation must not be greater than $3.5 \AA$, the average $A_{\mathrm{N}-\mathrm{HN}-\mathrm{O}}$ $\left(\left\langle A_{\mathrm{N}-\mathrm{HN}-\mathrm{O}}\right\rangle\right)$ must not be less than $125^{\circ}$, and $\left\langle A_{\mathrm{N}-\mathrm{HN}-\mathrm{O}}\right\rangle$ minus one standard deviation must not be less than $110^{\circ}$. Sixteen hydrogen bonds were assigned using the above criteria. Ten additional hydrogen bonds in helical regions were assigned by criteria slightly relaxed in distance or angle requirement, but not in both, in which $\left\langle d_{\mathrm{NO}}\right\rangle$ must not be greater than $4.0 \AA,\left\langle d_{\mathrm{NO}}\right\rangle$ plus one standard deviation must not be greater than $4.5 \AA$, or $\left\langle A_{\mathrm{N}-\mathrm{HN}-\mathrm{O}}\right\rangle$ must not be less than $115^{\circ}$, and $\left\langle A_{\mathrm{N}-\mathrm{HN}-\mathrm{O}}\right\rangle$ minus one standard deviation must not be less than $110^{\circ}$. This procedure resulted in the assignment of hydrogen bonds involving 39 of the 52 slow-exchanging backbone amide protons. Each hydrogen bond was constrained by the amide proton to carbonyl oxygen atom (1.8 to $2.2 \AA)$ and the amide nitrogen atom to carbonyl oxygen atom ( 2.8 to $3.2 \AA$ ) distances.

The calculation strategy used the hybrid distance geometry-simulated dynamical annealing methods (Nilges et al., 1988) as implemented in the program XPLOR 3.1 (Brünger, 1988, 1992), with parameters in the file parallhdg.pro modified to correct the planarity of the Arg guanidino group. Substructures were produced initially, followed by simulated annealing with all atoms. The structures were then subjected to cycles of simulated annealing using progressively decreasing initial temperatures and longer cooling times. Analysis of the structures was carried out using the tools available in XPLOR and the program DSSP (Kabsch \& Sander, 1983). Surface areas were calculated using the XPLOR implementation of the method of Lee \& Richards (1971) with a probe size of $1.4 \AA$. The molecular dimensions were calculated using CHARMM (Brooks et al., 1983), while the structural alignments with GM-CSF and IL-5 were optimized with O (Jones et al., 1991) using coordinate files 1gmf.pdb and 1hul.pdb. Structural illustrations were produced using INSIGHT (Biosym, San Diego), MOLSCRIPT (Kraulis, 1991), and RIBBONS 2.5 (Carson, 1991).

\section{Analysis of backbone dynamics}

Cross-peak heights were measured in Triad (Tripos Associates, St Louis, MO). $T_{1}$ and $T_{2}$ values were determined by a weighted non-linear least-squares procedure to fit the cross-peak intensities to a single exponential decay law, and the uncertainty in the fitted parameters was estimated from 500 Monte Carlo simulations as described by Palmer et al. (1991). For residues that exhibit resolved chemical shift heterogeneity, cross-peak intensities were analyzed individually; the model-free analysis used the averaged values of $T_{1}, T_{2}$ and NOE. When one-half of the difference between the relaxation parameter values $\left(T_{1}, T_{2}\right.$ or NOE) for the two populations was greater than the largest of their uncertainties, then this difference was used as the uncertainty for the model-free analysis; otherwise, the largest of the two uncertainties was used. If only one cross-peak could be resolved sufficiently to obtain intensity information, the relaxation data on the resolved signal was used to represent that residue. Twenty residues exhibited resolved heterogeneous amide nitrogenamide hydrogen cross-peaks. The differences in $T_{1}$ values of the two sets of cross-peaks were found to fall within the experimental uncertainties for all 20 residues, as did $T_{2}$ values for 13 of the 20 residues and NOE values for 16 of the 20 residues. Six residues displayed $T_{2}$ differences that exceeded uncertainties by up to $60 \%$, while one exceeded the uncertainty by twofold. Four residues had NOE differences greater than the experimental uncertainties by 0.5 to tenfold; only two of them overlapped with those that had large $T_{2}$ differences. These findings indicate that the averaging procedure described above gives a reasonably accurate description of the dynamic behavior of the backbone despite the existence of chemical shift heterogeneity.

The relaxation data were analyzed using the model-free formalism of Lipari \& Szabo (1982), or the extension of 
this method developed by Clore et al. (1990), as implemented in the model-free analysis program of Palmer et al. (1991). After an initial estimate of the global tumbling time $\tau_{\mathrm{m}}$ from the ratio $T_{1} / T_{2}$, the $T_{1}, T_{2}$ and NOE data for each residue were tested in models that contain: (1) $S^{2}$ only; (2) $\left(S^{2}, \tau_{\mathrm{e}}\right)$; (3) $\left(S^{2}, R_{\mathrm{ex}}\right)$; (4) $\left(S^{2}, \tau_{\mathrm{e}}, R_{\mathrm{ex}}\right)$ and (5) $\left(S_{\mathrm{f}}^{2}, S_{\mathrm{s}}^{2}, \tau_{\mathrm{s}}\right)$, respectively, where $S^{2}$ is the order parameter, which reflects the extent of the ${ }^{1} \mathrm{H}-{ }^{15} \mathrm{~N}$ internuclear unit vector motion, $\tau_{\mathrm{e}}$ refers to an effective correlation time, which reflects the time scale of the internal motion of the ${ }^{1} \mathrm{H}-{ }^{15} \mathrm{~N}$ internuclear vector, $R_{\mathrm{ex}}$ is a rate constant for other pseudo-first-order relaxation processes, and $S_{\mathrm{f}}^{2}$ and $S_{\mathrm{s}}^{2}$ are order parameters for rapid and slow time-scale internal motions in the two-time scale formalism (see Clore et al. (1990) for detailed definitions). The simplest model was chosen from among these five in which all three experimental relaxation parameters could be fitted within 1.96 times the experimental uncertainties. With the appropriate models determined for each residue, the global tumbling time, and the local internal motion parameters were optimized simultaneously. Tables listing all of the relaxation parameters and their estimated uncertainties are available upon request.

\section{Acknowledgements}

We thank Drs John Likos and Neena Summers for helpful discussions, Professor Lewis Kay of the University of Toronto for providing us with many pulse sequences, John Roman and Norm Hoffman for assistance with computer programming, and Professor Art Palmer of Columbia University for providing us with the programs to analyze the relaxation data. We also gratefully acknowledge the advice and encouragement of Dr John McKearn and the Synthokine Project Team, and the support and assistance of the Monsanto St Louis NMR Consortium.

\section{References}

Abdel-Meguid, S. S., Shieh, H.-S., Smith, W. W., Dayringer, H. E., Violand, B. N. \& Bentle, L. A. (1987). Three-dimensional structure of a genetically engineered variant of porcine growth hormone. Proc. Natl Acad. Sci. USA, 84, 6434-6437.

Azam, M., Erdjument-Bromage, H., Kreider, B. L., Xia, M., Quelle, F., Basu, R., Saris, C., Tempst, P., Ihle, J. N. \& Sandler, C. (1995). Interleukin-3 signals through multiple isoforms of STAT5. EMBO J. 14, 1402-1411.

Bagley, C. J., Woodcock, J. M., Hercus, T. R., Shannon, F. M. \& Lopez, A. F. (1995). Interaction of GM-CSF and IL-3 with the common $\beta$-chain of their receptors. J. Leukocyte Biol. 57, 739-746.

Banks, M., Graber, P., Proudfoot, A. E. I., Arod, C. Y., Allet, B., Bernard, A. R., Sebille, E., McKinnon, M., Wells, T. N. C. \& Solari, R. (1995). Soluble interleukin- 5 receptor $\alpha$-chain binding assays: use for screening and analysis of interleukin-5 mutants. Anal. Biochem. 230, 321-328.

Bazan, J. F. (1990). Haemopoietic receptors and helical cytokines. Immunol. Today, 11, 350-354.

Bazan, J. F. (1992). Unraveling the structure of IL-2. Science, 257, 410-412.

Biesma, B., Willemse, P. H. B., Mulder, N. H., Sleijfer, D. Th., Gietema, J. A., Mull, R., Limburg, P. C., Bourma, J., Vallenge, E. \& de Vries, E. G. E. (1992). Effects of interleukin-3 after chemotherapy for advanced ovarian cancer. Blood, 80, 1141-1148.

Brooks, B. R., Bruccoleri, R. E., Olafson, B., States, D. J., Swaminathan, S. \& Karplus, M. (1983). CHARMM: a program for macromolecular energy, minimization, and dynamics calculations. J. Comput. Chem. 4, 187-217.

Brown, C. R., Pihl, C. E. \& Kaushansky, K. (1994). Mapping of human granulocyte-macrophage-colonystimulating-factor domains interacting with the human granulocyte-macrophage-colony-stimulatingfactor-receptor $\alpha$-subunit. Eur. J. Biochem. 225, 873-880.

Brünger, A. T. (1988). Crystallographic refinement by simulated annealing. Application to a $2.8 \AA$ resolution structure of aspartate aminotransferase. J. Mol. Biol. 203, 803-816.

Brünger, A. T. (1992). X-PLOR Version 3.1, A System for $X$-ray Crystallography and $N M R$, Yale University Press, New Haven, CT.

Carson, M. (1991). Ribbons 2.0. J. Appl. Crystallog. 24, 958-961.

Clore, G. M. \& Gronenborn, A. M. (1987). Determination of three-dimensional structures of proteins in solution by nuclear magnetic resonance spectroscopy. Protein Eng. 1, 275-288.

Clore, G. M, Driscoll, P. C., Wingfield, P. T. \& Gronenborn, A. M. (1990). Analysis of the backbone dynamics of interleukin-1 $\beta$ using two-dimensional inverse detected heteronuclear ${ }^{15} \mathrm{~N}-{ }^{1} \mathrm{H}$ NMR spectroscopy. Biochemistry, 29, 7387-7401.

Constantine, K. L., Friedrichs, M. S., Goldfarb, V., Jeffrey, P. D., Sheriff, S. \& Mueller, L. (1993). Characterization of the backbone dynamics of an anti-digoxin antibody $\mathrm{V}_{\mathrm{L}}$ domain by inverse detected ${ }^{1} \mathrm{H}^{-15} \mathrm{~N}$ NMR: comparisons with X-ray data for the Fab. Proteins: Struct. Funct. Genet. 15, 290-311.

Denzlinger, C., Walther, J., Wilmanns, W. \& Gerhartz, H. H. (1993). Interleukin-3 enhances the endogenous leukotriene production. Blood, 81, 2466-2468.

de Vos, A. M., Ultsch, M. \& Kossiakoff, A. A. (1992). Human growth hormone and extracellular domain of its receptor: crystal structure of the complex. Science, 255, 306-312.

Diederichs, K., Boone, T. \& Karplus, P. A. (1991). Novel fold and putative receptor binding site of granulocyte-macrophage colony-stimulating factor. Science, 254, 1779-1782.

Ding, D. X.-H., Rivas, C. I., Heaney, M. L., Raines, M. A., Vera, J. C. \& Golde, D. W. (1994). The alpha subunit of the human granulocyte-macrophage colony-stimulating factor receptor signals for glucose transport via a phosphorylation-independent pathway. Proc. Natl Acad. Sci. USA, 91, 2537-2541.

Dorssers, L. C., Mostert, M. C., Burger, H., Janssen, C., Lemson, P. J., van Lambalgen, R., Wagemaker, G. \& van Leen, R. W. (1991). Receptor and antibody interactions of human interleukin-3 characterized by mutational analysis. J. Biol. Chem. 266, 21310-21317.

Ealick, S. E., Cook W. J., Vijay-Kumar, S., Carson, M., Nagabhushan, T. L., Trotta, P. P. \& Bugg, C. E. (1991). Three-dimensional structure of recombinant human interferon-gamma. Science, 252, 698-702.

Farrow, N. A., Muhandiram, R., Singer, A. U., Pascal, S. M., Kay, C. M., Gish, G. Shoelson, S. E., Pawson, T., Forman-Kay, J. D. \& Kay, L. E. (1994). Backbone dynamics of a free and a phosphopeptide-complexed Src homology 2 domain studied by ${ }^{15} \mathrm{~N}$ NMR relaxation. Biochemistry, 33, 5984-6003. 
Feng, Y., Klein, B. K., Vu, L., Aykent, S. \& McWherter, C. A. (1995). ${ }^{1} \mathrm{H},{ }^{13} \mathrm{C}$, and ${ }^{15} \mathrm{~N}$ NMR resonance assignments, secondary structure, and backbone topology of a variant of human interleukin-3. Biochemistry, 34, 6540-6551.

Forman-Kay, J. D., Gronenborn, A. M., Kay, L. E., Wingfield, P. T. \& Clore, G. M. (1990). Studies on the solution conformation of human thioredoxin using heteronuclear ${ }^{15} \mathrm{~N}-{ }^{1} \mathrm{H}$ nuclear magnetic resonance spectroscopy. Biochemistry, 29, 1566-1572.

Freeman, J. J., Parr, G. R., Hecht, R. I., Morris, J. C. \& McKearn, J. P. (1991). Secondary structure of human interleukin-3. Int. J. Biochem. 23, 353-360.

Ganser, A. (1993). Clinical results with recombinant human interleukin-3. Cancer Invest. 11, 212-218.

Ganser, A., Lindemann, A., Seipelt, G., Ottman, O. G., Hermann, F., Eder, M., Frisch, J., Schulz, G., Mertlesmann, R. \& Hoelzer, D. (1990). Effects of recombinant human interleukin-3 in patients with normal hematopoiesis and in patients with bone marrow failure. Blood, 76, 666-676.

Gearing, D. P., King, J. A., Gough, N. M. \& Nicola, N. A. (1989). Expression cloning of a receptor for human granulocyte-macrophage colony-stimulating factor. EMBO J. 8, 3667-3676.

Gough, N. M. \& Kelso, A. (1989). GM-CSF expression is preferential to multi-CSF (IL-3) expression in murine $\mathrm{T}$ lymphocyte clones. Growth Factors, 1, 287-298.

Graber, P., Proudfoot, A. E. I., Talabot, F., Bernard, A., McKinnon, M., Banks, M., Fattah, D., Soalri, R., Peitsch, M. C. \& Wells, T. N. C. (1995). Identification of key charged residues of human interleukin- 5 in receptor binding and cellular activation. J. Biol. Chem. 270, 15762-15769.

Haak-Frendscho, M., Arai, N., Arai, K.-I., Baeza, M. L., Finn, M. \& Kaplan, A. P. (1988). Human recombinant granulocyte-macrophage colony-stimulating factor and interleukin 3 cause basophil histamine release. J. Clin. Invest. 82, 17-20.

Hayashida, K., Kitamura, T., Gorman, D. M., Arai, K., Yokota, T. \& Miyajima, A. (1990). Molecular cloning of a second subunit of the receptor for human granulocyte-macrophage colony-stimulating-factor (GM-CSF): reconstitution of a high-affinity GM-CSF receptor. Proc. Natl Acad. Sci. USA, 87, 9655-9659.

Herrmann, F., Brugger, W., Kanz, L. \& Mertelsmann, R. (1992) . In vivo biology and therapeutic potential of hematopoietic growth factors and circulating progenitor cells. Semin. Oncol. 19, 422-431.

Hill, C. P., Osslund, T. D. \& Eisenberg, D. (1993). The structure of granulocyte-colony-stimulating factor and its relationship to other growth factors. Proc. Natl Acad. Sci. USA, 90, 5167-5171.

Ikura, M., Kay, L. E., Tschudin, R. \& Bax, A. (1990). Three-dimensional NOESY-HMQC spectroscopy of a ${ }^{13}$ C-labeled protein. J. Magn. Reson. 86, 204-209.

Jones, T. A., Zou, J. Y., Cowan, S. W. \& Kjeldgaard, M. (1991). Improved methods for binding protein models in electron density maps and the location of errors in these models. Acta Crystallog. sect. A, 47, 110-119.

Kabsch, W. \& Sander, C. (1983). Dictionary of protein secondary structure: pattern recognition of hydrogen-bonded and geometrical features. Biopolymers, 22, 2577-2637.

Kaushansky, K., Shoemaker, S. G., Broudy, V. C., Lin, N. L., Matous, J. V., Alderman, E. M., Aghajanian, J. D., Szklut, P. J., VanDyke, R. E., Pearce, M. K. \&
Abrams, J. S. (1992). Structure-function relationships of interleukin-3. J. Clin. Invest. 90, 1879-1888.

Kay, L. E. \& Bax, A. (1990). New methods for the measurement of $\mathrm{NH}-\mathrm{C}^{\alpha} \mathrm{H}$ coupling constants in ${ }^{15}$ N-labeled proteins. J. Magn. Reson. 86, 110-126.

Kay, L. E., Torchia, D. A. \& Bax, A. (1989). Backbone dynamics of proteins as studied by ${ }^{15} \mathrm{~N}$ inverse detected heteronuclear NMR spectroscopy. Biochemistry, 28, 8972-8979.

Kay, L. E., Keifer, P. \& Saarinen, T. (1992). Pure absorption gradient enhanced heteronuclear single quantum correlation spectroscopy with improved sensitivity. J. Am. Chem. Soc. 114, 10663-10664.

Kay, L. E., Xu, G. Y. \& Yamazaki, T. (1994). Enhancedsensitivity triple-resonance spectroscopy with minimal $\mathrm{H}_{2} \mathrm{O}$ saturation. J. Magn. Reson. sect. A, 109, 129-133.

Kitamura, T. \& Miyajima, A. (1992). Functional reconstitution of the human interleukin-3 receptor. Blood, 80 , 84-90.

Kitamura, T., Sato, N., Arai, K.-I. \& Miyajima, A. (1991). Expression cloning of the human IL-3 receptor cDNA reveals a shared $\beta$ subunit for the human IL-3 and GM-CSF receptors. Cell, 66, 1165-1174.

Kördel, J., Skelton, N. J., Akke, M., Palmer, A. G. \& Chazin, W. J. (1992). Backbone dynamics of calciumloaded calbindin $\mathrm{D}_{9 \mathrm{k}}$ studies by two-dimensional proton-detected ${ }^{15} \mathrm{~N}$ NMR spectroscopy. Biochemistry, 31, 4856-4866.

Kraulis, P. J. (1991). MOLSCRIPT: a program to produce both detailed and schematic plots of protein structures. J. Appl. Crystallog. 24, 946-950.

Kraulis, P. J., Clore, G. M., Nilges, M., Jones, T. A., Pettersson, G., Knowles, J. \& Gronenborn, A. M. (1989). Determination of the three-dimensional solution structure of the C-terminal domain of cellobiohydrolase I from Trichoderma reesei. A study using nuclear magnetic resonance and hybrid distance geometry-dynamical simulated annealing. Biochemistry, 28, 7241-7257.

Lee, B. \& Richards, F. M. (1971). The interpretation of protein structures: estimation of static accessibility. J. Mol. Biol. 55, 379-400.

Liepinsh, E., Otting, G. \& Wüthrich, K. (1992). Contributions from hydration of carboxylate groups to the spectrum of water-polypeptide proton-proton Overhauser effects in aqueous solution. J. Biomol. NMR, 2, 447-465.

Lipari, G. \& Szabo, A. (1982). Model-free approach to the interpretation of nuclear magnetic resonance relaxation in macromolecules. J. Am. Chem. Soc. 104, 4546-4559.

Lokker, N. A., Strittmatter, U., Steiner, C., Fagg, B., Graff, P., Kocher, H. P. \& Zenke, G. (1991a). Mapping the epitopes of neutralizing anti-human IL-3 monoclonal antibodies: implications for structure-activity relationship. J. Immunol. 146, 893-898.

Lokker, N. A., Zenke, G., Strittmatter, U., Fagg, B. \& Mora, N. R. (1991b). Structure-activity relationship study of human interleukin-3: role of the C-terminal region for biological activity. $E M B O \mathrm{~J} .10$, 2125-2131.

Lopez, A. F., Eglinton, J. M., Gillis, D., Park, L. S., Clark, S. \& Vadas, M. A. (1989). Reciprocal inhibition of binding between interleukin-3 and granulocyte colony-stimulating factor to human eosinophils. Proc. Natl Acad. Sci. USA, 86, 7022-7026.

Lopez, A. F., Shannon, M. F., Barry, S., Phillips, J. A., Cambareri, B., Dottore, M., Simmons, P. \& Vadas, 
M. A. (1992a). A human interleukin 3 analog with increased biological and binding activities. Proc. Natl Acad. Sci. USA, 89, 11842-11846.

Lopez, A. F., Shannon, M. F., Hercus, T., Nicola, N. A., Cambareri, B., Dottore, M., Layton, M. J., Eglinton, L. \& Vadas, M. A. (1992b). Residue 21 of human granulocyte-macrophage colony-stimulating factor is critical for biological activity and for high but not low affinity binding. EMBO J. 11, 909-916.

Lovejoy, B., Cascio, D. \& Eisenberg, D. (1993). Crystal structure of canine and bovine granulocyte-colony stimulating factor (G-CSF). J. Mol. Biol. 234, 640-653.

Marion, D., Kay, L. E., Sparks, S. W., Torchia, D. A. \& Bax, A. (1989). Three-dimensional heteronuclear NMR of ${ }^{15}$ N-labeled proteins. J. Am. Chem. Soc. 111, 15151517.

McKay, D. B. (1992). Response to commentary on unraveling the structure of IL-2. Science, 257, 412-413.

Metcalf, D. \& Nicola, N. A. (1995). The Hemopoietic ColonyStimulating Factors. From Biology to Clinical Applications, Cambridge University Press, Cambridge, UK.

Milburn, M. V., Hassell, A. M., Lambert, M. H., Jordan, S. R., Proudfoot, A. E. I., Graber, P. \& Wells, T. N. C. (1993). A novel dimer configuration revealed by the crystal structure at $2.4 \AA$ resolution of human interleukin-5. Nature, 363, 172-176.

Mott, H. R., Driscoll, P. C., Boyd, J., Cooke, R. M., Weir, M. P. \& Campbell, I. D. (1992). Secondary structure of human interleukin 2 from 3D heteronuclear NMR experiments. Biochemistry, 31, 7741-7744.

Mui, A., Muto, A., Sakamaki, K., Sato, N., Kinoshita, T., Watanabe, S., Yokota, T., Arai, K. \& Miyajima, A. (1994). Function of the common $\beta$ subunit of the GM-CSF/IL-3/IL-5 receptors. Advan. Expt. Med. Biol. $365,217-223$.

Nilges, M. W. (1995). Calculation of protein structures with ambiguous distance restraints. Automated assignment of ambiguous NOE cross-peaks and disulphide connectivities. J. Mol. Biol. 245, 645-660.

Nilges, M. W., Clore, G. M. \& Gronenborn, A. M. (1988). Determination of three-dimensional structures of proteins from interproton distance data by hybrid distance geometry-dynamical simulated annealing calculations. FEBS Letters, 229, 317-324.

Nishida, J., Yoshida, M., Arai, K. \& Yokota, T. (1991). Definition of a GC-rich motif as regulatory sequence of the IL-3 gene by CLE2/GC box of the GM-CSF gene in T cell activation. Int. Immunol. 3, 245-254.

Olins, P. O., Bauer, S. C., Braford-Goldberg, S., Sterbenz, K., Polazzi, J. O., Caparon, M. H., Klein, B. K., Easton, A. M., Paik, K., Klover, J. A., Thiele, B. R. \& McKearn, J. P. (1995). Saturation mutagenesis of human interleukin-3. J. Biol. Chem. 270, 23754-23760.

Palmer, A. G., Rance, M. \& Wright, P. E. (1991). Intramolecular motions of a zinc finger DNA-binding domain from Xfin characterized by proton-detected natural abundance ${ }^{13} \mathrm{C}$ heteronuclear NMR spectroscopy. J. Am. Chem. Soc. 113, 4371-4380.

Pandit, J., Bohm, A., Jancarik, J., Halenbeck, R., Koths, K. \& Kim, S.-H. (1992). Three-dimensional structure of dimeric human recombinant macrophage colonystimulating factor. Science, 258, 1358-1362.

Parry, D., Minasian, E. \& Leach, S. (1988). Conformational homologies among cytokines: interleukins and colony stimulating factors. J. Mol. Recog. 1, 107-110.

Parry, D., Minasian, E. \& Leach, S. (1991). Cytokine conformations: predictive studies. J. Mol. Recog. 4, 63-75.
Pascal, S. M., Muhandiram, D. R., Yamazaki, T., Forman-Kay, J. D. \& Kay, L. E. (1994). Simultaneous acquisition of ${ }^{15} \mathrm{~N}$ - and ${ }^{13} \mathrm{C}$-edited $\mathrm{NOE}$ spectra of proteins dissolved in $\mathrm{H}_{2}$ O. J. Magn. Reson. sect. B, 103, 197-201.

Powers, R., Garrett, D. S., March, C. J., Frieden, E. A., Gronenborn, A. M. \& Clore, G. M. (1992). Three-dimensional solution structure of human interleukin-4 by multidimensional heteronuclear magnetic resonance spectroscopy. Science, 256, 16731677.

Quelle, F., Sato, N., Witthuhn, B., Inhorn, R., Eder, M., Miyajima, A., Griffin, J. \& Ihle, J. (1994). JAK2 associates with the beta $\mathrm{c}$ chain of the receptor for granulocyte-macrophage colony-stimulating factor, and its activation requires the membrane-proximal region. Mol. Cell. Biol. 14, 4335-4341.

Redfield, C., Boyd, J., Smith, L. J., Smith, R. A. G. \& Dobson, C. M. (1992). Secondary structure and topology of human interleukin 4 in solution. Biochemistry, 31, 10431-10437.

Robinson, R. C., Grey, L. M., Staunton, D. Vankelecom, H., Vernallis, A. B., Moreau, J.-F., Stuart, D. I., Heath, J. K. \& Jones, E. Y. (1994). The crystal structure and biological function of leukemia inhibitory factor: implications for receptor binding. Cell, 77, 1101-1016.

Rozwarski, D. A., Gronenborn, A. M., Clore, G. M., Bazan, J. F., Bohm, A., Wlodawer, A., Hatada, M. \& Karplus, P. A. (1994). Structural comparisons among the short-chain helical cytokines. Structure, 2, 159-173.

Schneider, D. M., Dellwo, M. J. \& Wand, A. J. (1992). Fast internal main-chain dynamics of human ubiquitin. Biochemistry, 31, 3645-3652.

Schrader, J. W. \& Clark-Lewis, I. (1982). A T cell-derived factor stimulating multipotential hemopoietic stem cells; molecular weight and distinction from $\mathrm{T}$ cell growth factor and T cell-derived granulocyte-macrophage colony-stimulating factor. J. Immunol. 129, 30-35.

Senda, T., Shimazu, T., Matsuda, S., Kawano, G., Shimizu, H., Nakamura, K. T. \& Mitsui, Y. (1992). Threedimensional crystal structure of recombinant murine interferon- $\beta$. EMBO J. 11, 3193-3201.

Shanafelt, A. B., Johnson, K. E. \& Kastelein, R. A. (1991a). Identification of critical residues in human and mouse granulocyte-macrophage colony-stimulating factor and their involvement in species specificity. J. Biol. Chem. 266, 13804-13810.

Shanafelt, A. B., Miyajima, A., Kitamura, T. \& Kastelein, R. A. (1991b). The amino-terminal helix of GM-CSF and IL-5 governs high affinity binding to their receptors. EMBO J. 10, 4105-4112.

Smith, L. J., Redfield, C., Boyd, J., Lawrence, G. M. P., Edwards, R. G., Smith, R. A. G. \& Dobson, C. M. (1992). Human interleukin 4: the solution structure of a four-helix bundle protein. J. Mol. Biol. 224, 899-904.

Somers, W., Ultsch, M., de Vos, A. M. \& Kossiakoff, A. A. (1994). The X-ray structure of a growth hormoneprolactin receptor complex. Nature, 372, 478-481.

Stone, M. J., Fairbrother, W. J., Palmer, A. G., Reizer, J., Saier, M. H. \& Wright, P. E. (1992). Backbone dynamics of the Bacillus subtilis glucose permease IIA domain determined from ${ }^{15} \mathrm{~N}$ NMR relaxation measurements. Biochemistry, 31, 4394-4406.

Takaki, S., Murata, Y., Kitamura, T., Miyajima, A., Tominaga, A. \& Takatsu, K. (1993). Reconstitution of the functional receptors for murine and human interleukin 5. J. Expt. Med. 177, 1523-1529. 
Tavernier, J., Devos, R., Cornelis, S., Tuypens, T., Van der Heyden, J., Fiers, W. \& Plaetinck, G. (1991). A human high affinity interleukin-5 receptor (IL5R) is composed of an IL5-specific $\alpha$ chain and a $\beta$ chain shared with the receptor for GM-CSF. Cell, 66, 1175-1184.

Tavernier, J., Guisez, Y., Devos, R., Plaetinck, G., Heyden, J. van der \& Oefner, C. (1994). Analysis of human interleukin-5 mutants: implications for receptor activation. Challenges Mod. Med. 8, 99-107.

Thomas, J. W., Baum, C. M., Hood, W. F., Klein, B. K., Monahan, J. B., Paik, K., Staten, N., Abrams, M. \& McKearn, J. P. (1995). Potent interleukin-3 receptor agonist with selectively enhanced hematopoietic activity relative to recombinant human interleukin-3. Proc. Natl Acad. Sci. USA, 92, 3779-3783.

Ultsch, M. H., Somers, W., Kossiakoff, A. A. \& de Vos, A. M. (1994). The crystal structure of affinitymatured human growth hormone at $2 \AA$ resolution. J. Mol. Biol. 236, 286-299.

Walter, M. R. \& Nagabhushan, T. L. (1995). Crystal structure of interleukin 10 reveals an interferon $\gamma$-like fold. Biochemistry, 34, 12118-12125.

Walter, M. R., Cook, W. J., Ealick, S. E., Nagabhushan, T. L., Trotta, P. P. \& Bugg, C. E. (1992). Three-dimensional structure of recombinant human granulocytemacrophage colony-stimulating factor. J. Mol. Biol. 224, 1075-1085.

Werner, J. M., Breeze, A. L., Kara, B., Rosenbrock, G., Boyd, J., Soffe, N. \& Campbell, I. D. (1994). Secondary structure and backbone dynamics of human granulocyte colony-stimulating factor in solution. Biochemistry, 33, 7184-7192.
Wlodawer, A., Pavlovsky, A. \& Gutschina, A. (1992). Crystal structure of human recombinant interleukin4 at $2.25 \AA$ resolution. FEBS Letters, 309, 59-64.

Woodcock, J. M., Zacharakis, B., Plaetinck, G., Bagley, C. J., Qiyu, S., Hercus, T. R., Tavernier, J. \& Lopez, A. F. (1994). Three residues in the common $\beta$ chain of the human GM-CSF, IL-3 and IL-5 receptors are essential for GM-CSF and IL-5 but not IL-3 high affinity binding and interact with Glu21 of GM-CSF. EMBO J. 13, 5176-5185.

Wüthrich, K. (1986). NMR of Proteins and Nucleic Acids. Wiley, New York.

Yang, Y.-C., Ciarletta, A. B., Temple, P. A., Chung, M. P., Kovacic, S., Witek-Glannotti, J. S., Leary, A. C., Kriz, R., Donahue, R. E., Wong, G. G. \& Clark, S. C. (1986). Human IL-3 (multi-CSF): identification by expression cloning of a novel hematopoietic growth factor related to murine IL-3. Cell, 47, 3-10.

Zink, T., Ross, A., Ambrosius, D., Rudolph, R. \& Holak, T. A. (1992). Secondary structure of human granulocyte colony-stimulating factor derived from NMR spectroscopy. FEBS Letters, 314, 435-439.

Zink, T., Ross, A., Lüers, K., Cieslar, C., Rudolph, R. \& Holak, T. A. (1994). Structure and dynamics of the human granulocyte colony-stimulating factor determined by NMR spectroscopy. Loop mobility in a four-helix-bundle protein. Biochemistry, 33, 84538463.

Zuiderweg, E. R. P. \& Fesik, S. W. (1989). Heteronuclear three-dimensional NMR spectroscopy of the inflammatory protein C5a. Biochemistry, 28, 23872391.

Edited by P. E. Wright 